\title{
Electromagnetic Radiation Generated by Arcing in Low Density Plasma
}

Boris V. Vayner, Dale C. Ferguson, David B. Snyder, and C.V. Doreswamy

Lewis Research Center

Cleveland, Ohio

Prepared for the

XVII International Symposium on Discharges and Electrical Insulation in Vacuum sponsored by the American Physical Society

Berkeley, California, July 21-26, 1996

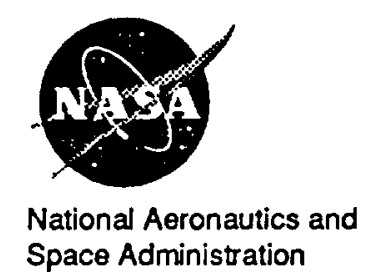





\title{
ELECTROMAGNETIC RADIATION GENERATED BY ARCING IN LOW DENSITY PLASMA
}

\author{
Boris V. Vayner", Dale C. Ferguson ${ }^{*}$, David B. Snyder ${ }^{*}$, and C. V. Doreswamy ${ }^{\$ *}$ \\ National Aeronautics and Space Administration \\ Lewis Research Center, Cleveland, Ohio 44135
}

\begin{abstract}
$\underline{\text { Abstract }}$
An unavoidable step in the process of space exploration is to use high-power, very large spacecraft launched into Earth orbit. Obviously, the spacecraft will need powerful energy sources. Previous experience has shown that electrical discharges occur on the surfaces of a high-voltage array, and these discharges (arcs) are undesirable in many respects. Moreover, any high voltage conductor will interact with the surrounding plasma, and that interaction may result in electrical discharges between the conductor and plasma (or between two conductors with different potentials, for example, during docking and extravehicular activity). One very important aspect is the generation of electromagnetic radiation by arcing. To prevent the negative influence of electromagnetic noise on the operation of spacecraft systems, it seems necessary to determine the spectra and absolute levels of the radiation, and to determine limitations on the solar array bias voltage that depend on the parameters of LEO plasma and the technical requirements of the spacecraft equipment. This report describes the results of an experimental study and computer simulation of the electromagnetic radiation generated by arcing on spacecraft surfaces. A large set of high quality data was obtained during the Solar Array Module Plasma Interaction Experiment (SAMPIE, flight STS-62) and ground test. These data include the amplitudes of current, pulse forms, duration of each arc, and spectra of plasma waves.

A theoretical explanation of the observed features is presented in this report too. The elaborated model allows us to determine the parameters of the electromagnetic noise for different frequency ranges, distances from the arcing site, and distinct kinds of plasma waves.
\end{abstract}

"National Research Council-NASA Research Associate at Lewis Research Center.

${ }^{+}$Chief, Space Environment Effects Branch.

${ }^{2}$ Physicist, Space Environment Effects Branch.

${ }^{s}$ Professor, Tuskegee University, Tuskegee, Alabama. 



\section{Nomenclature}

$a \quad$ arc length, $\mathrm{m}$

$B$ magnetic field strength, $G$ s

$C$ capacitance, $\mathrm{F}$

$E, E \quad$ electrical field strength, $\mathrm{V} / \mathrm{m}$

$f$ frequency of plasma density fluctuations, $\mathrm{Hz}$

$f_{L H} \quad$ lower hybrid resonance frequency, $\mathrm{Hz}$

$f_{U H} \quad$ upper hybrid resonance frequency, $\mathrm{Hz}$

$F_{e} \quad$ electron gyrofrequency

$F_{i} \quad$ ion gyrofrequency, $\mathrm{Hz}$

$I, i \quad$ arc current, $\mathrm{A}$

$I_{\max } \quad$ arc peak current, $\mathrm{A}$

$J, J \quad$ electric current density, $\mathrm{A} / \mathrm{m}^{2}$

$\boldsymbol{k}, \boldsymbol{k} \quad$ wave vector, $\mathrm{m}^{-1}$

$k_{B} \quad$ Boltzman constant, J/K

$n_{e} \quad$ electron number density, $\mathrm{m}^{-3}$

$n_{i} \quad$ ion number density, $\mathrm{m}^{-3}$

$N_{\text {arc }} \quad$ number of arcs per one experiment

$p \quad$ neutral gas pressure, $\mathrm{Pa}$

$R$ distance from spacecraft surface, $\mathrm{m}$

$t$ time, $\mathrm{s}$

$T_{e} \quad$ electron temperature, $\mathrm{eV}$

$T_{g} \quad$ neutral gas temperature, $\mathrm{K}$

$T_{i} \quad$ ion temperature, $\mathrm{K}$

$U \quad$ LP output voltage, $\mathrm{V}$

$v_{e} \quad$ electron thermal speed, $\mathrm{m} / \mathrm{s}$

$V$ bias voltage, $\mathrm{V}$

$\gamma$ the decrement of plasma waves, $s^{-1}$

$\Delta t \quad$ duration of an arc, $s$

$\varphi \quad$ the angle between the wave vector $k$ and the Earth magnetic field $B$

$\Phi(f) \quad$ arc current spectrum, $\mathrm{A} / \mathrm{MHz}$

$\lambda$ the wave length, $m$

$\Lambda_{c}$ the Debye length, $m$

$\vartheta$ angle between the Earth magnetic field and the arc current

$\sigma \quad$ cross section, $\mathrm{m}^{2}$

$\tau_{\exp } \quad$ duration of individual experiment with arcing, $s$

$\omega=2 \pi f$ frequency, $\mathrm{Hz}$

\section{Introduction}

Forty years experience of space exploration show that large spacecraft, such as Space Station Freedom, will be deployed in low Earth orbit to provide a basis for further achievements in space science and space technology. Obviously, large and complicated 
structures demand powerful energy sources to keep all systems in operating condition. We believe that high-voltage solar arrays will serve as the primary electrical energy sources for a long time in the future. However, previous experience has shown that electrical discharges occur on the surfaces of a high-voltage array ${ }^{14}$, and these discharges (arcs) are undesirable in many respects. One very important aspect is the generation of electromagnetic radiation (EMR) by arcing. ${ }^{5}$ To prevent the negative influence of electromagnetic noise on the operation of spacecraft systems, it seems necessary to determine the spectra and absolute levels of the radiation, and to determine limitations on the solar array bias voltage that depend on the parameters of LEO plasma and the technical requirements of the spacecraft equipment. ${ }^{6}$ Moreover, any high voltage conductor will interact with the surrounding plasma, and that interaction may result in electrical discharges between the conductor and plasma (or between two conductors with different potentials, for example, during docking and extravehicular activity).

A number of experiments have been done during last decade to determine arcing rate and threshold, the magnitude and duration of current pulses, the dependence of arcing rate on bias voltage and plasma density, and the spectrum and intensity of generated electromagnetic radiation. An extensive review of space experiments is published in the paper by Hastings ${ }^{7}$, and new data obtained in the last two years may be found in papers by Hillard and Ferguson ${ }^{8}$ and Kuninaka ${ }^{9}$. The advantage of space experiments is obvious: solar cells (or samples of solar cells) operate in the natural plasma environment during many days or even months, and both short time and long time processes caused by interaction with plasma can be analyzed. But there are always strong limitations on the volume and types of data that might be collected because of technical requirements for experimental devices employed on spacecraft. On the contrary, ground experiments have the advantage of a controlled environment and unlimited choice of measurements that may be done. In other words, these two kinds of experiments are complementary to each other, and we use the results of the Solar Array Module Plasma Interaction Experiment (SAMPIE) $^{10}$ and the Langmuir Probe Experiment (LPE) ${ }^{11}$ to create and verify a theoretical model that allows us to determine the parameters of the electromagnetic noise for different frequency ranges, distance from the arcing site, and distinct kinds of plasma waves.

\section{Basic equations}

The discharges that occur between negatively biased solar cells and the surrounding plasma can generate electromagnetic radiation with a broad spectrum and considerable amplitude. In order to obtain an appropriate expression connecting the discharge current characteristics with EMR spectra we start from Maxwell's equations:

$\operatorname{cur} 1 \mathrm{~B}=-\frac{1}{\mathrm{c}} \cdot \frac{\partial \mathrm{B}}{\partial t} ; \quad \operatorname{cur} 1 \mathrm{~B}=\frac{4 \pi}{\mathrm{c}} \mathrm{J}+\frac{1}{\mathrm{c}} \cdot \frac{\partial \mathrm{E}}{\partial \mathrm{t}} ; \quad \operatorname{divE}=4 \cdot \pi \rho ; \quad \operatorname{div} \mathrm{B}=0$

If we consider waves of length much shorter than the scale of the plasma density gradient, and if we disregard changes in the electron number density due to arcing, we can apply the Fourier transformation to the equation set (1): 
$\mathbf{E}(\mathbf{x}, t)=\frac{1}{(2 \pi)^{2}} \cdot \int \mathrm{E}(\omega, \mathbf{x}) \cdot \exp (-i \omega t+i \mathbf{k x}) \cdot d^{3} k d \omega$

It is easy to obtain the following relation between the Fourier transformations of the electrical field strength and the current density:

$\left(\frac{\omega^{2}}{c^{2}}-k^{2}\right) \cdot E(\omega, \mathbf{k})+\mathbf{k} \cdot(\mathbf{k} \cdot \mathrm{E}(\omega, \mathbf{k}))=-\frac{4 \pi \cdot i \omega}{c^{2}} \mathrm{~J}(\omega, \mathbf{k})$

The equation (3) allows us to find (in principle) the electromagnetic field if the source current is known. However, the main problem is to determine the current density $\mathbf{J}(\omega, \mathbf{k})$ for all of space. Obviously, we can represent the current density as the sum of two terms: i) arc current; ii) current that is induced in the plasma by the electric field.

The spatial distribution of the current density has the following form ${ }^{12}$ :

$\mathbf{J}(\mathbf{x}, \mathbf{t})=\mathbf{J}_{\mathbf{a}}(\mathbf{x}, \mathbf{t}) \mathrm{H}(\mathbf{x})+\mathbf{J}_{\mathrm{p}}(\mathbf{x}, \mathbf{t})[1-\mathbf{H}(\mathbf{x})]$

where $\mathrm{H}(\mathbf{x})$ is a step function defined by the expressions:

$H(x)=1$ for all points $x$ inside arc, and $H(x)=0$ elsewhere.

Within the framework of the linear theory, the current in the plasma is proportional to the field strength

$\mathbf{J}_{\mathbf{p}}(\omega, \mathbf{k})=\hat{\sigma}(\omega, \mathbf{k}) \cdot \mathbf{E}(\omega, \mathbf{k})$

where $\hat{\sigma}(\omega, \mathbf{k})=\sigma_{i j}(\omega, \mathbf{k}) ; \quad(i, j=1,2,3)$ is the conductivity tensor.

The Fourier transformation of the current density can be written in the form:

$$
\begin{aligned}
& \mathrm{J}(\omega, \mathbf{k})=\frac{1}{(2 \pi)^{2}} \cdot \int H(\mathbf{x})\left[\mathrm{J}_{\mathrm{a}}(\mathbf{x}, t)-\mathrm{J}_{\mathrm{p}}(\mathrm{x}, t)\right] \cdot \exp (i \omega t-i \mathbf{k x}) \cdot d^{3} x d t+ \\
& \frac{1}{(2 \pi)^{2}} \cdot \int \mathrm{J}_{\mathrm{p}}(\mathrm{x}, t) \cdot \exp (i \omega t-i \mathbf{k x}) \cdot d^{3} x d t
\end{aligned}
$$

The last term in Eq.(6) is equal to $J_{p}(\omega, k)$. The first term in the Eq. (6) can be simplified by taking into account the inequality $\mathbf{J}_{\mathbf{p}}<<\mathbf{J}_{\mathbf{2}}$ that is valid inside the arc.

The dielectric tensor of the plasma and the conductivity tensor are related according to the equation : ${ }^{13}$

$$
\hat{\mathbf{R}}(\omega, \mathbf{k})=\hat{\mathbf{I}}+\frac{4 i \pi}{\omega} \cdot \hat{\sigma}(\omega, \mathbf{k})
$$


where $\hat{\mathrm{I}}=\delta_{i j}$ is the identity matrix.

Finally, the master equation has the form:

$$
\left(\frac{\omega^{2}}{c^{2}} \cdot \hat{\mathbf{k}}-k^{2}\right) \xi+\mathbf{k} \cdot(\mathbf{k} \cdot \mathbf{E})=-\frac{4 i \pi \omega}{c^{2}} \mathbf{J}_{a}(\omega, \mathbf{k})
$$

The dielectric tensor has a complicated structure even for a cold magnetized plasma. ${ }^{14}$ It can be written in the following form:

$$
\hat{K}_{i j}=P \cdot b_{i} \cdot b_{j}+S \cdot\left(\delta_{i j}-b_{i} b_{j}\right)-i D \cdot \varepsilon_{i j k} b_{k}
$$

where $P, S$, and $D$ are functions of frequency only. These functions can be represented as expressions with a strong dependence on the plasma resonance frequencies: ${ }^{12}$

$P=1-\frac{f_{e}^{2}}{f^{2}} ; \quad S=\frac{\left(f^{2}-f_{L H}^{2}\right) \cdot\left(f^{2}-f_{U H}^{2}\right)}{\left(f^{2}-F_{i}^{2}\right) \cdot\left(f^{2}-F_{e}^{2}\right)} ; \quad D=-\frac{f \cdot f_{e}^{2} \cdot F_{e}}{\left(f^{2}-F_{i}^{2}\right) \cdot\left(f^{2}-F_{e}^{2}\right)}$

$b_{i}=\frac{B_{i}}{|\mathrm{~B}|} ; \quad \varepsilon_{i j k}$ is completely antisymmetric tensor of rank three, and $f=\omega / 2 \pi$.

It should be noted that tensor $\mathbf{K}$ in the equation (8) doesn't include an Ion Acoustic Wave branch because the ion temperature $T_{\text {ion }}=0$ by definition of the cold plasma.

The formal solution of the Eq.(8) can be obtained in general form:

$E(\omega, \mathbf{k})=\hat{\mathbf{T}}^{-1}\left(-\frac{4 i \pi \omega}{c^{2}} \cdot \mathbf{J}_{a}(\omega, \mathbf{k})\right)$

where $\hat{\mathbf{T}}=\frac{\omega^{2}}{c^{2}} \cdot \hat{\mathbf{K}}-k^{2} \cdot \hat{\mathbf{I}}+\mathbf{k} \cdot(\mathbf{k} \cdot)$, and $\hat{\mathbf{T}} \cdot \hat{\mathbf{T}}^{-1}=\hat{\mathbf{I}}$

The dispersion relations for electromagnetic waves are determined by zeros of the determinant of the tensor $\mathbf{T}_{\mathrm{ij}}$, and the electromagnetic field can be calculated by using the inverse Fourier transformation of the expression (10). However, to perform these calculations much algebra must be done. It seems more reasonable to calculate the electromagnetic field by using the approximation of the dielectric tensor within different frequency ranges. But, before starting this procedure we derive the Fourier components of the arc current density.

\section{Arc current}

The determination of the right term in the Eq. (8) requires a physical model of the 
arc current. As it was observed in some experiments by measurement of UV radiation from $\operatorname{arcs}^{3}$, the diameter of the discharge region is very small $(\approx 500 \mu \mathrm{m})$, and this value is much less than any wavelength that we suggest to be considered $(\lambda \geq 10 \mathrm{~cm})$. Moreover, we can estimate the upper limit of the arc cross section as

$S_{\max }=\frac{I_{\max }}{J_{\min }}=\frac{I_{\max }}{n_{e} e v_{e}}$

The amplitude of current $I_{\max }$ depends on many factors but it has never been higher than $\sim 10 \mathrm{~A}$ for numerous space and ground experiments. ${ }^{10,11}$ If we suggest that neutral gas should be fully ionized in the arc channel, the electron number density for LEO flight conditions is calculated according to the equality : $n_{a}=N \approx 10^{11}-10^{12} \mathrm{~cm}^{-3}$. The actual number density of electrical charge carriers should be much higher because secondary ionization caused by collision of electrons with neutral atoms (molecules) seems possible if one takes into account the desorption of gas from the cell surfaces. ${ }^{15,16}$ The electron velocity is certainly less than the maximum value $v_{\max }=\left(\frac{2 \mathrm{eV}}{\mathrm{m}_{\mathrm{c}}}\right)^{1 / 2} \approx 10^{\circ} \frac{\mathrm{cm}}{\mathrm{s}}$. Thus, we get the following estimate for an upper limit on the arc diameter: $d \approx S_{\max }^{1 / 2} \leq 1 \mathrm{~cm}$. Obviously, the real diameter is much less than the estimate above. Therefore, the arc current can be written in the following form:

$\mathbf{J}_{a}(t, x, y, z)=\Phi(t) \cdot J(z) \cdot \delta(x) \cdot \delta(y) \cdot \mathbf{n}_{s}$

where $\delta(x)$ is the Dirac delta function, and $\mathbf{n}_{\mathbf{z}}$ is the unit vector in the z-direction.

The temporal evolution of the arc current was studied in numerous experiments. ${ }^{3,11,17,18}$ Discharges on negatively biased solar cell samples were investigated during the space experiment SAMPIE .,10 The results of the statistical analysis and real curves $\Phi(t)$ will be shown below, but to an order of magnitude we know that the peak current is $\sim(1-10) A$, and the pulse duration is $\sim(1-20) \mu$ s.

We model the function $\Phi(t)$ as in Fig. 1 .

The current pulse form can be characterized by three parameters: rise time $\tau$, plateau duration $\Delta t$, and exponential relaxation time $T$. Of course, the spectrum $\Phi(f)$ depends on these parameters. Computer simulation shows that the spectrum falls by $40 \mathrm{~dB}$ at frequency $f=40 \mathrm{MHz}$ if $\tau=0$, and the spectrum goes down by $60 \mathrm{~dB}$ at the same frequency if $\tau=0.1 \mu \mathrm{s}$. An example of the spectrum is shown in Fig. 2 .

The wave form of a current pulse was measured with sampling interval 5 ns in the course of LP experiments. ${ }^{11}$ One example of such measurements is shown in Fig.3 


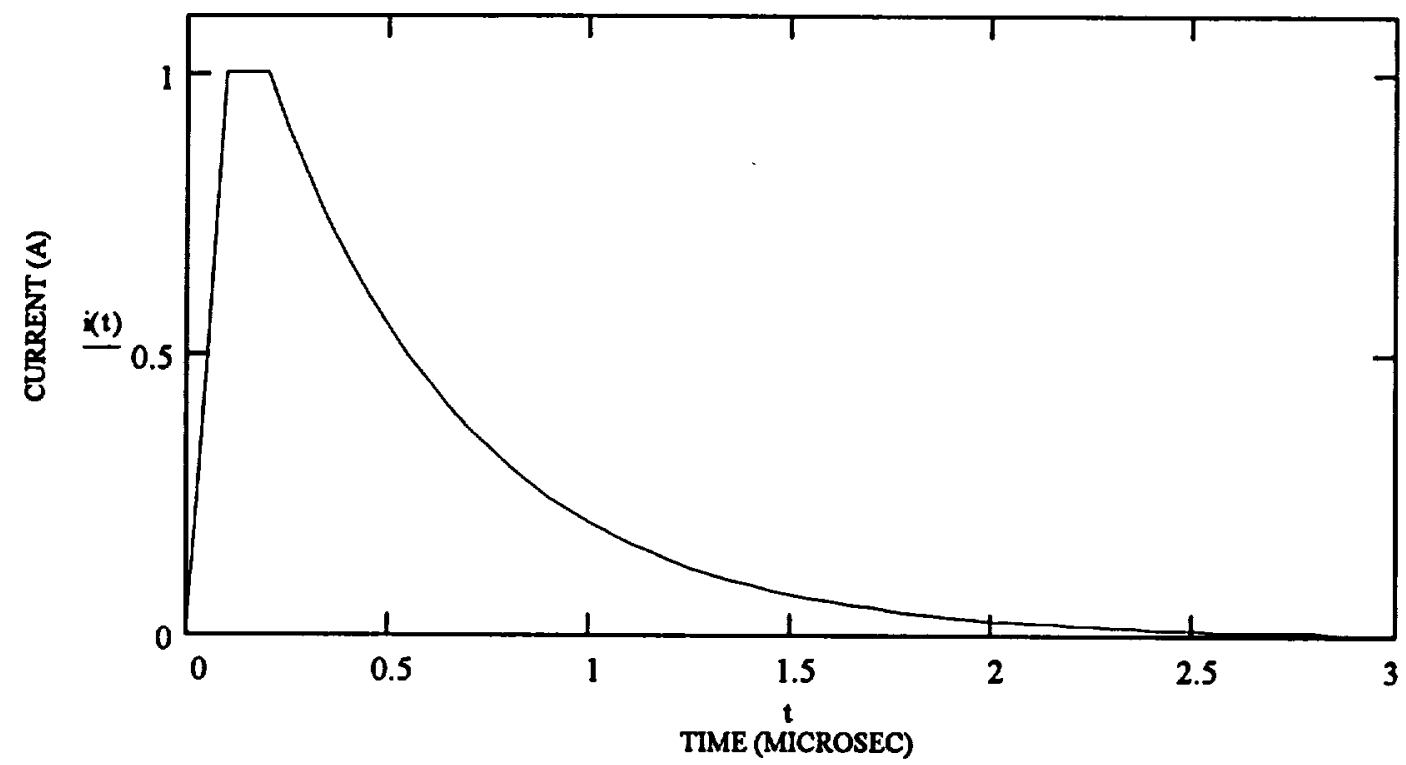

Fig.1. The temporal evolution of the discharge current (model).

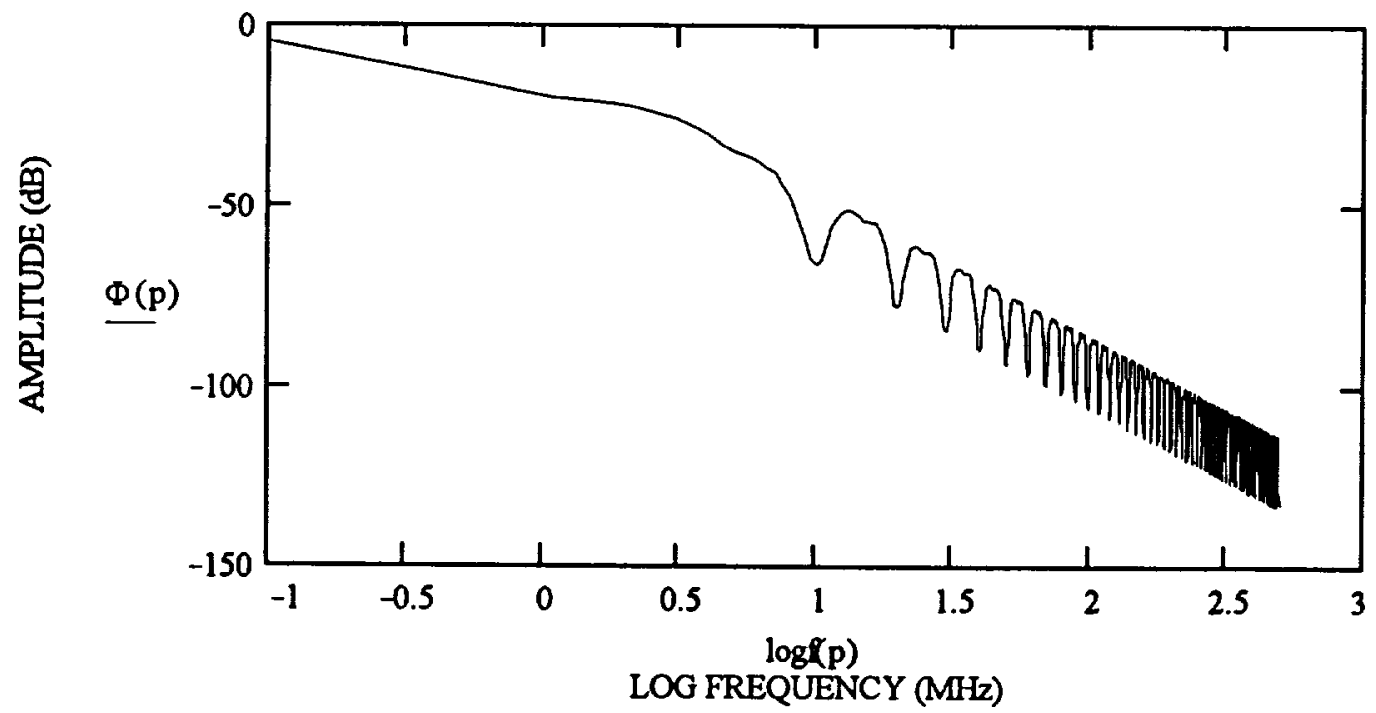

Fig.2 The spectrum of the current pulse that is shown in Fig.1 


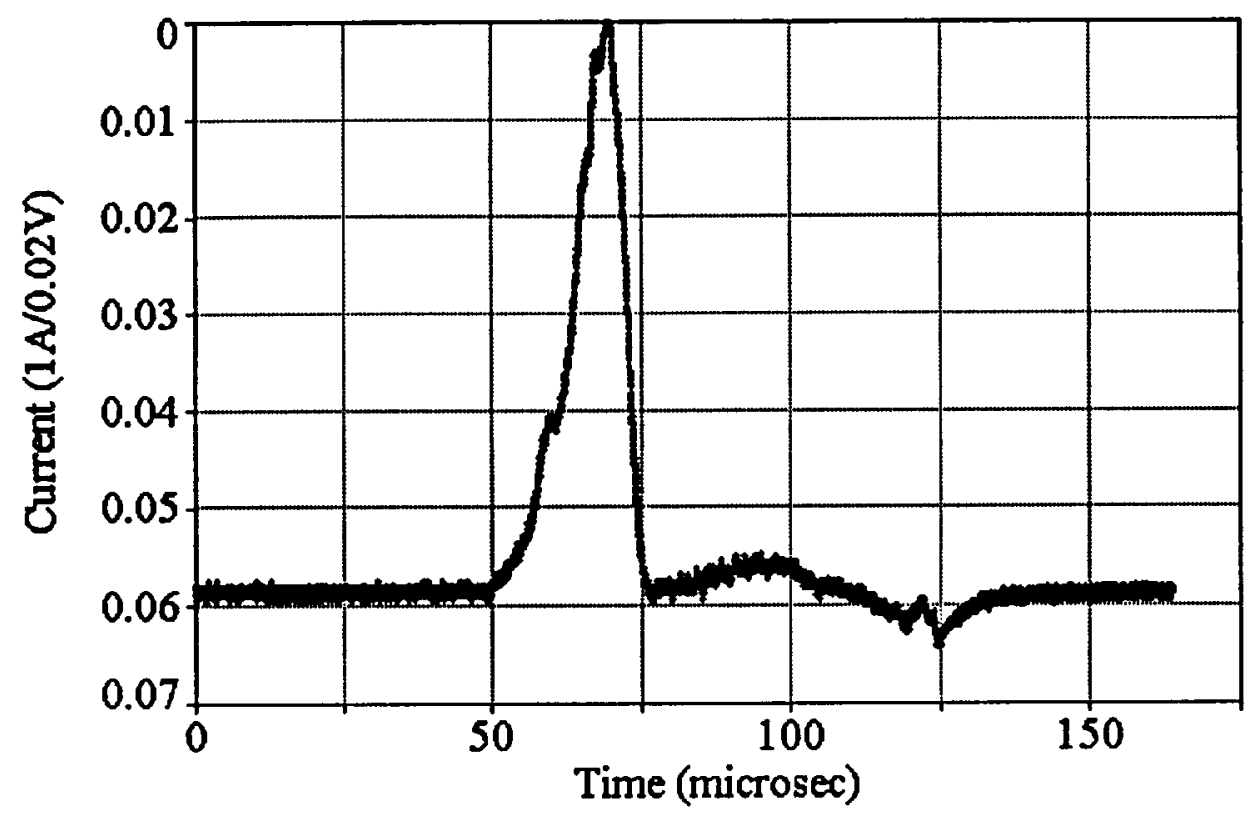

Fig. 3. Current pulse wave form measured during the ground experiment LPA_7.

It is seen that the rise time is approximately equal to $3 \mu \mathrm{s}$, and the pulse duration slightly exceeds $10 \mu \mathrm{s}$. These data can be explained by the special experimental setup when an additional capacitor was installed between the anodized aluminium plate and ground to simulate the capacitance of real large solar array. The Fourier spectrum of current pulse is demonstrated in Fig. 4. The essential difference between the model spectrum (Fig. 2) and observed spectrum (Fig. 4) lies in the high-frequency region. The magnitude of harmonics does not fall below $70 \mathrm{db}$ for frequencies $f \leq 50 \mathrm{MHz}$. It is caused by short time fluctuations in the arc current, and it is important for further computations because the plasma frequency does not exceed $20 \mathrm{MHz}$ for LEO conditions.

If we suggest that the arc channel has a simple structure like straight line perpendicular to the conductive plate, the spatial Fourier transformation of the current density can be represented by a simple formula: ${ }^{19}$

$J(k)=\frac{1}{k_{3}}\left(\sin k_{3} a+i \cdot\left(1-\cos k_{3} a\right)\right)$

where $a$ is the arc length.

It is easy to see that the current $J(k)$ has maxima at wave numbers $k_{3(m)}=(2 m+1) / a$ $(m=0,1,2 \ldots)$. We may conclude that an arc operates like an ordinary half-wave vibrator immersed in the plasma when we consider the radiation of elecromagnetic waves. 


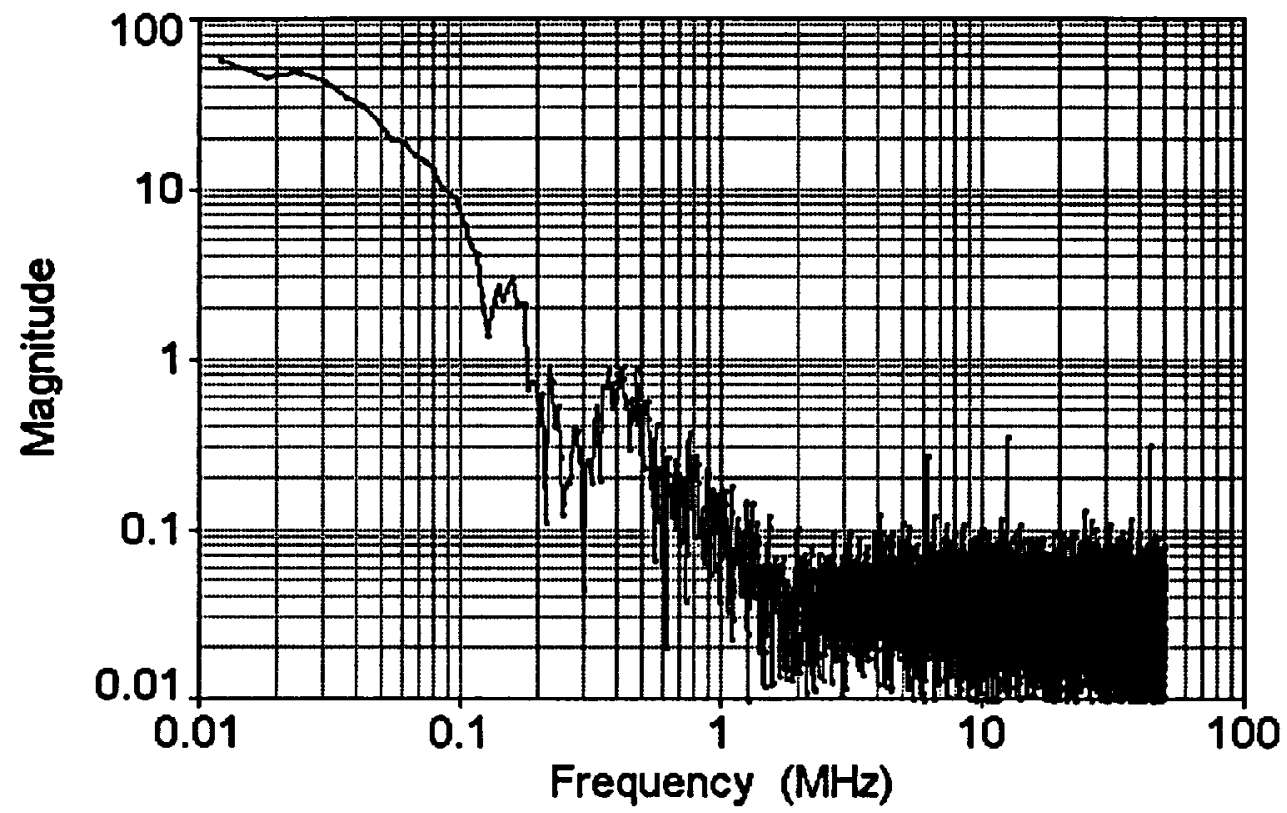

Fig. 4. The spectrum of current pulse shown in Fig. 3

\section{High frequency transverse waves}

We now begin our analysis of the electromagnetic radiation generated by arcing in the form of high frequency transverse waves. For LEO plasma, this means waves with frequencies $\beta>f_{e} \approx 20 \mathrm{MHz}$ and wave length limited by the value $\lambda=\frac{300}{f(M H z)} \ll 15 m$.

Because the length of an arc is not more than $10 \mathrm{~cm}^{*}$, the consideration below is valid within the frequency range $20<f<3000 \mathrm{MHz}$. The frequency spectrum of the electric field strength can be obtained from equation (10) after performing the inverse Fourier transformation:

$$
E(x, \omega)=\frac{1}{(2 \pi)^{3 / 2}} \cdot \int d^{3} k \cdot\left(-\frac{4 i \pi \omega}{c^{2}}\right) \cdot \frac{\Phi(\omega) \cdot a}{\frac{\omega^{2}}{c^{2}}-k^{2}} \cdot \mathbf{n}_{z} \cdot \exp (i \mathbf{k x})
$$

\footnotetext{
*This estimate is based on the experimental data obtained by Leung ${ }^{17}$ and our calculations of the arc length. According to Ref.(6), the arc length might be about equal to the plasma sheath size. This means that the parameter $a$ could be as large as one meter if the bias voltage reaches several hundred volts. We don't have the final answer in this problem.
} 
If we define the angle $\Theta=\cos ^{-1}\left(\frac{x \cdot n_{z}}{|x|}\right)$, we may write the strength of electric field in the form

$$
E(|x|, \Theta, \omega)=\frac{4 \pi \Phi(\omega) \cdot \omega \cdot a}{|x| \cdot c^{2}}\left[1-\cos ^{2} \Theta+\left(3 \cos ^{2} \Theta-1\right) \cdot\left(\frac{c^{2}}{\left.\omega^{2} \cdot|x|\right|^{2}}-\frac{i c}{\omega \cdot|k x|}\right)\right]
$$

To compare the calculated value (15) with available experimental data and the technical requirements on the level of the electromagnetic noise, it is convenient to represent the field strength in the units of $\mathrm{dB}^{*} \mu \mathrm{V} / \mathrm{m}^{*} \mathrm{MHz}$. It can be written in the following form:

$$
\mathrm{E}(x, \omega)=240+20 \cdot \log \left(\frac{E(|x|, \Theta, \omega)}{4 \pi \varepsilon_{0}}\right)
$$

where $\varepsilon_{0}=8.85^{*} 10^{-12} \mathrm{Cl} / \mathrm{V}^{*} \mathrm{~m}$ is the dielectric constant.

The spectrum (16) is shown in Fig. 5. To draw this chart we suggest the angle $\Theta=\pi / 2$, the current amplitude $I_{\max }=1 \mathrm{~A}$, the arc length $a=10 \mathrm{~cm}$, and the distance $x=1 \mathrm{~m}$. As a result, we have a quite good agreement with experimental data obtained by Leung ${ }^{s}$.

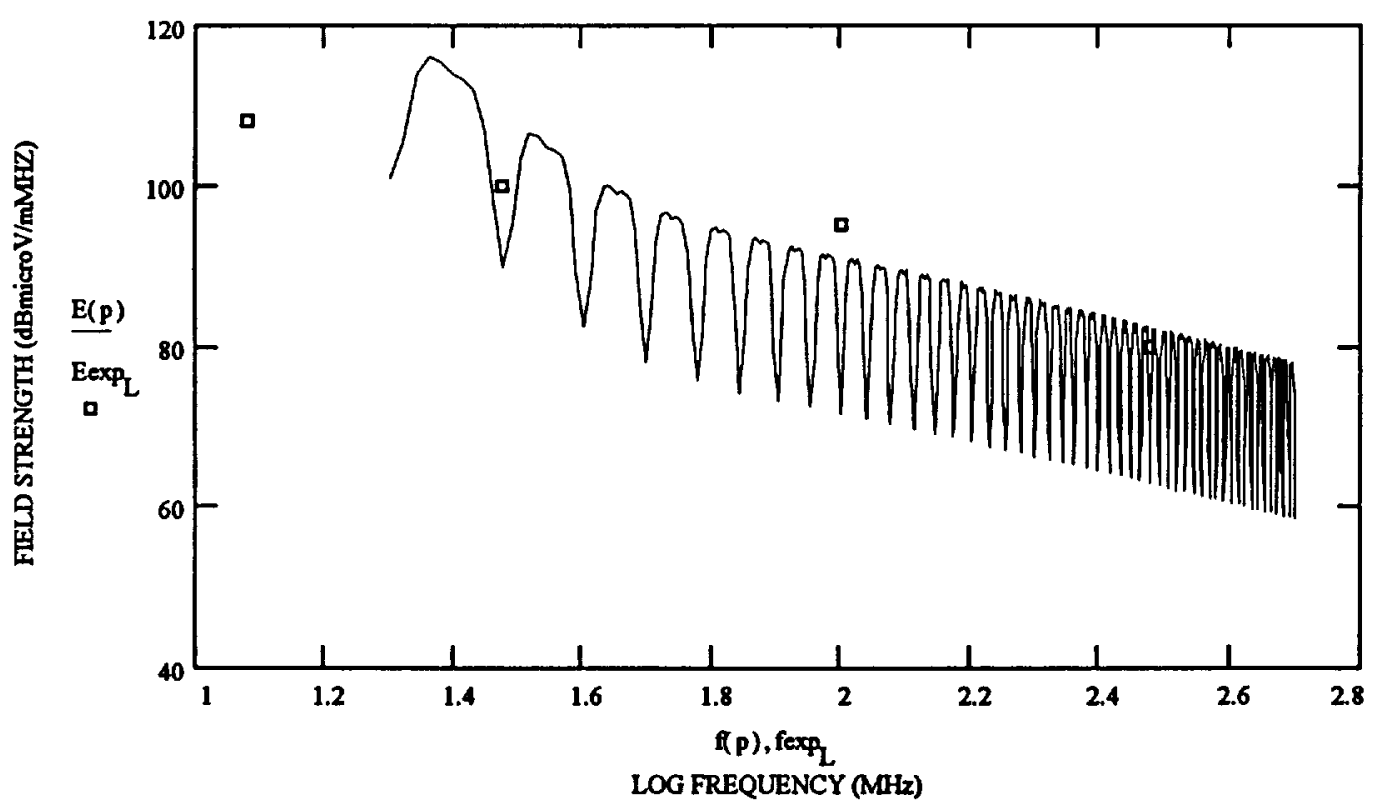

Fig. 5 The frequency spectrum of the electric field strength at distance $1 \mathrm{~m}$ from an arc with the peak current 1 A. $\square$ - experimental data from Ref.(5).

It should be noted that all of the oscillations that are seen in Fig. 5 were not measured in the mentioned experiments because the highest values of amplitudes from several measurements for each frequency range were reported. The level of the electromagnetic 
noise decreases by $20 \mathrm{~dB}$ for each decade of distance; thus, that level is less than the upper limit determined by technical requirements ${ }^{6}$ when distances are greater than $100 \mathrm{~m}$. Thus, the calculations show that the field strength depends on arc peak current, the current pulse form, and the distance from a discharge site. Because the arcing rate depends strongly on both bias voltage and plasma density ${ }^{2}$, an increase in operating voltage for solar cells will inevitably generate more intensive electromagnetic noise around the spacecraft, particularly in LEO conditions. In spite of the fact that the physical mechanism of arcing is not finally established yet, simple estimates can be made

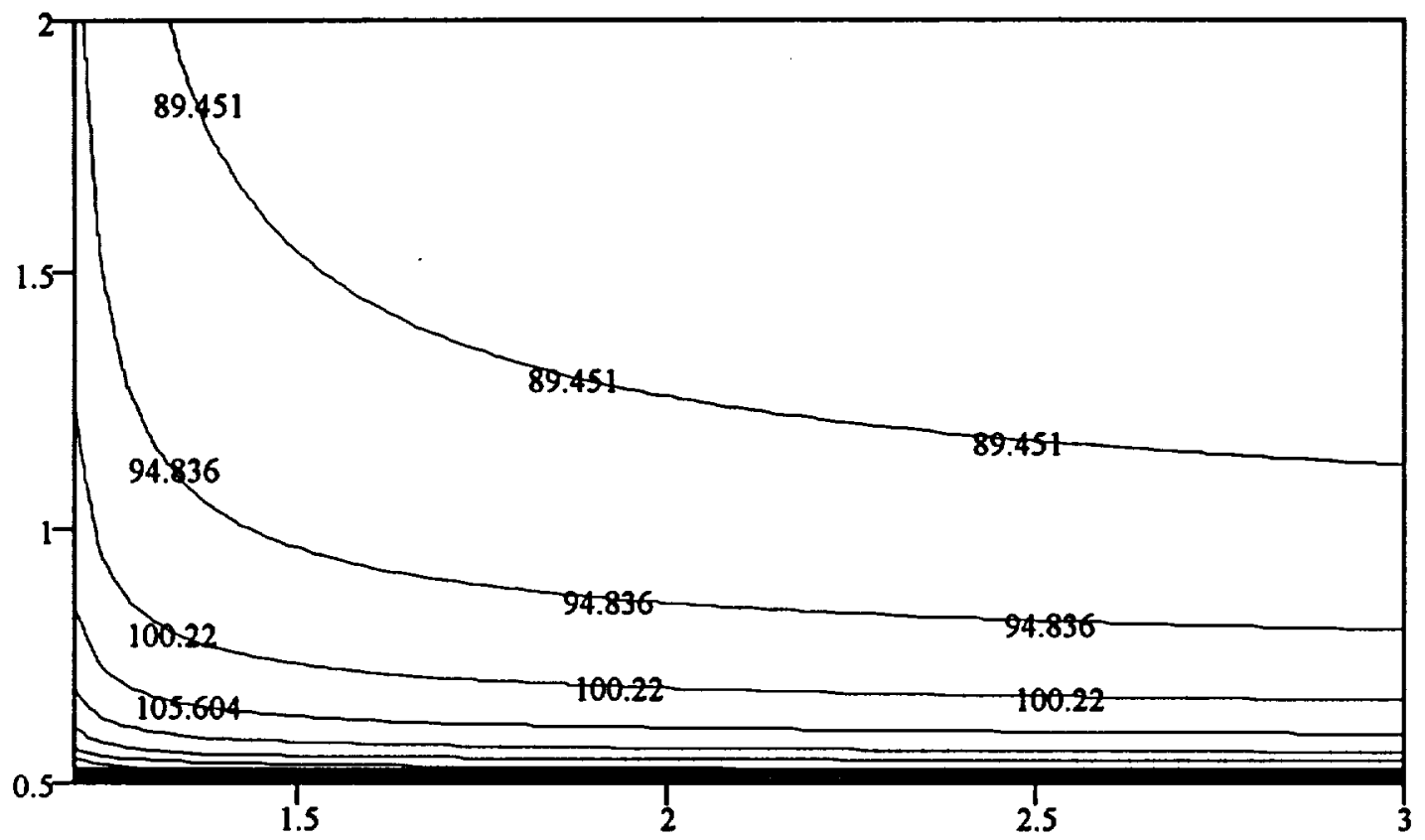

M

Fig. 6. Contour map of the electromagnetic field strength on $\log f$-logx plane.

regarding the expected peak current value. Really, an arc is an electrical disharge between two electrically charged bodies that can be considered as a capacitor with the capacitance $C$.

The transient current is determined by the obvious relation

$I=\frac{d Q}{d t}=C \cdot \frac{d V}{d t}$, where $Q$ is electrical charge, and $V$ is the voltage drop between the bodies.

The temporal rate of the voltage change can be estimated as $\frac{d V}{d t} \approx \frac{V_{\max }}{\tau}$. According to SAMPIE experimental data the peak voltage (it is equal to the bias voltage) $V_{\max }=400$ $600 \mathrm{~V}$, and the average discharge time $\tau=0.1-0.5 \mu \mathrm{s}$. Now it is possible to estimate the peak current $I_{\max }=(0.8-6) \cdot \frac{C}{10^{3} p F} \quad A$. The last result is in agreement with measured values (SAMPIE data, 1994). 


\section{Measurements of arc parameters}

Before beginning the computations of plasma waves it seems reasonable to show some results of the measurements of the arc peak current and duration of pulses that were obtained by SAMPIE and the LP experiment. The results of two different experiments (E_60-1 and E_64-1) are shown in Fig. 7 and Fig. 8 respectively. It is seen that the peak current was as high as $I_{\max }=3 \mathrm{~A}$, and the duration of pulse is equal to $0.2-0.4 \mu \mathrm{s}$ for most cases. The electrical charge that was lost by the sample of solar cells depends on the duration of pulse, and it ranged usually between 0.2 and $0.4 \mu \mathrm{Cl}$.

It should be mentioned that arcs with very different parameters were observed. For example, during the experiment E_48-1 five arcs were registered, and the peak current was no more than $0.6 \mathrm{~A}$ with approximately equal duration for each arc $(0.7 \mu \mathrm{s})$. Only one arc was observed during the experiment E_44-1: the peak current was equal to 1.73 $A$, and the duration was equal to $0.44 \mu \mathrm{s}$. Thus, the stochastic nature of the arcing onset demands consideration of the generated electromagnetic radiation within the framework of a statistical theory. The calculations above are useful as a first step to elaborate the theory of EMR generated by arcing on spacecraft surfaces.

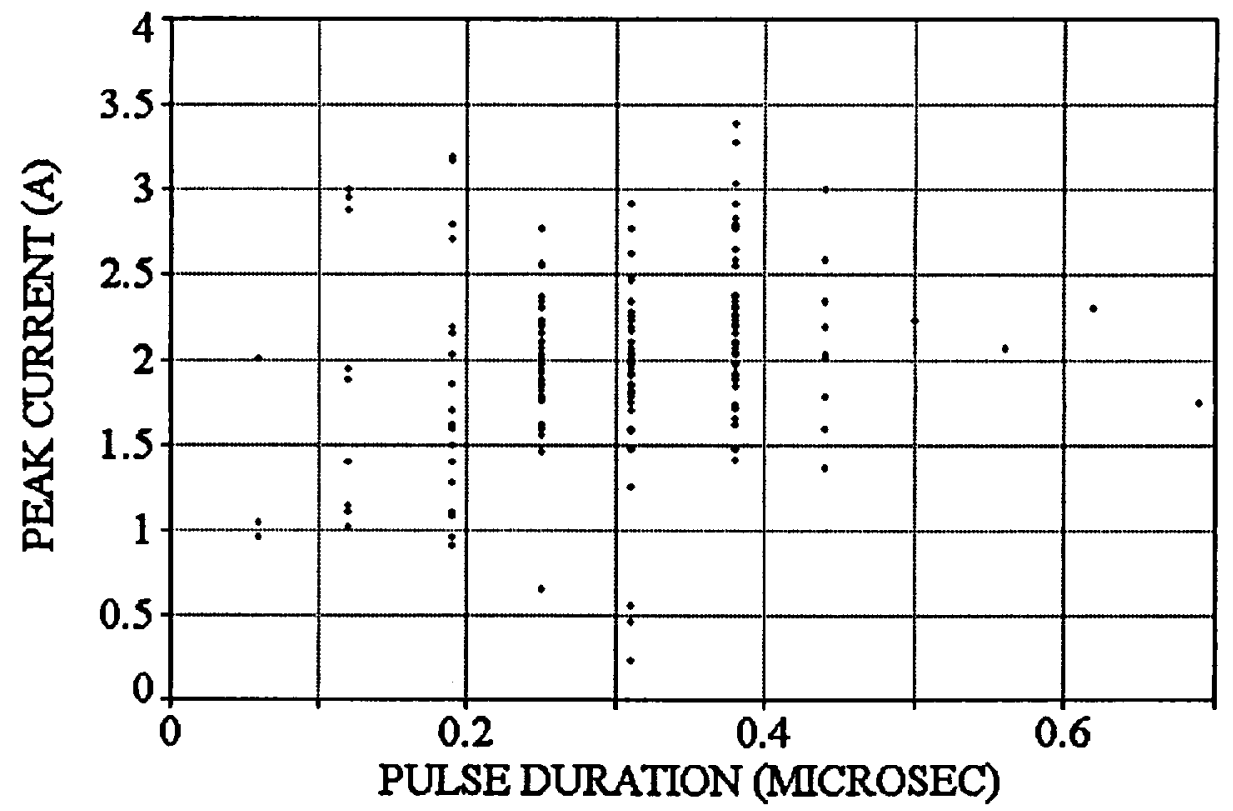

Fig.7a. Data from the Experiment $\# 60-1$. The bias voltage $V=400 \mathrm{~V}$, and 181 arcs were registered. 


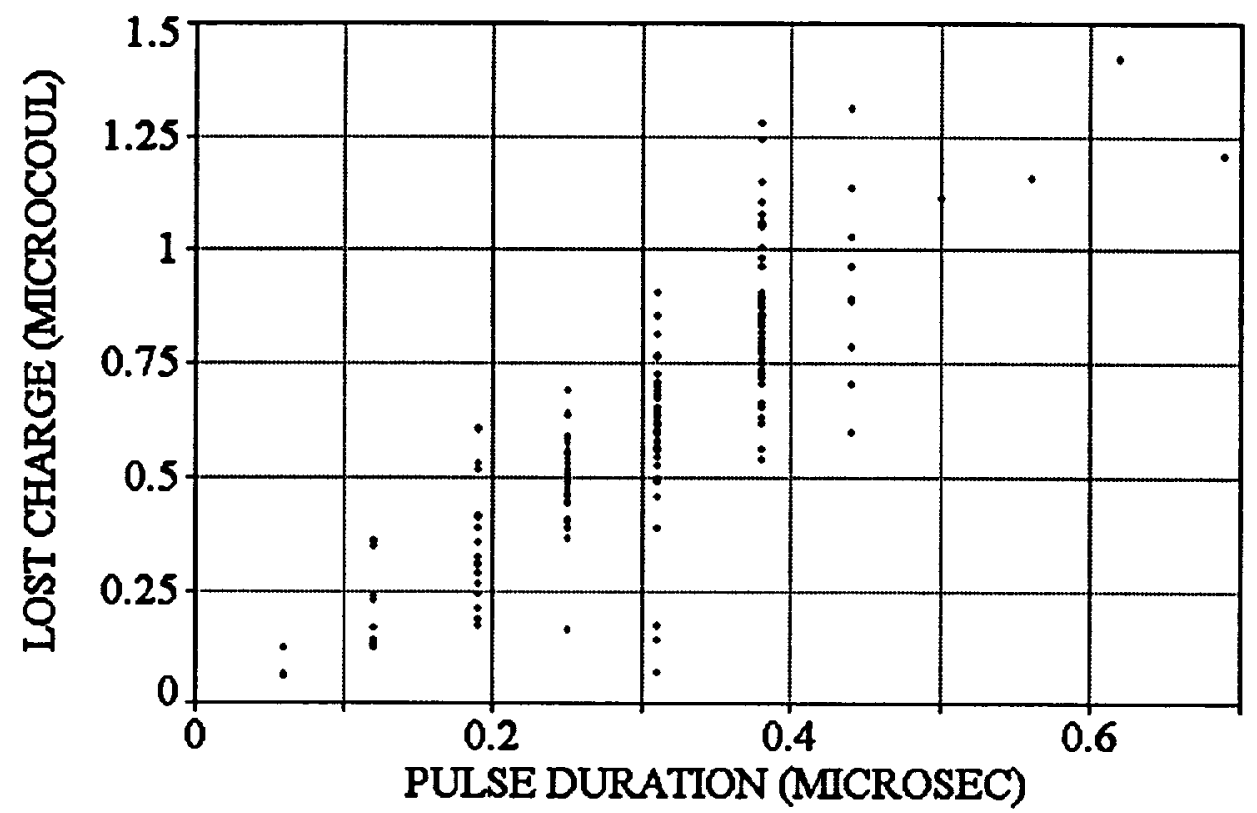

Fig. 7b. Lost charge vs. pulse duration for the same experiment. $A$ trend is clear (correlation coefficient $\operatorname{corr}(, T)=0.259$ ).

In order to obtain more details regarding the arcing process and plasma wave characteristics ground experiments were carried out. " A plate of anodized aluminum $(18 \times 18 \mathrm{~cm})$ was biased at $-275 \mathrm{~V}$ and mounted inside a vacuum tank with neutral gas pressure $p \approx 20 \mu$ Torr and electron number density $n_{\mathrm{q}} \sim 10^{6} \mathrm{~cm}^{-3}$. The electron temperature was approximately equal to $l \mathrm{eV}$, and the ion temperature could be estimated as $300 \mathrm{~K}$. Three Langmuir probes (A, B, and C) were placed in this tank at distances 55, 75, and 100 $\mathrm{cm}$ from the plate respectively. Arc current and the potential of one of the Langmuir probes were measured simultaneously. Experimental data were represented in a digital form with a sampling interval of $5 \mathrm{~ns}$ that allowed us to analyze fluctuations with frequencies up to $100 \mathrm{MHz}$.

As it was mentioned above, LP ground experiments were performed with an additional capacitor installed between a conducting plate and ground. The results of measurements are shown in Table 1. One can see from this table that there are no correlations between the electron number density and the value of electrical charge lost due to arcing. This means that we observed plasma waves in the background plasma, although there is some evidence of changes in electron number density in the vicinity of the Langmuir probes. We discuss these details below. The magnitude of the peak current increases with increasing of capacitance. This fact can be explained by the following estimates: peak current $I_{\max } \approx C V / \Delta t$, and the discharge time $\Delta t$ depends on plasma parameters and conducting plate material characteristics only. We should stress that the last statement is 
valid for an arc current high enough to initiate the secondary processes in the arc column. For the initial stages of the discharge the rise time grows with increasing capacitance.

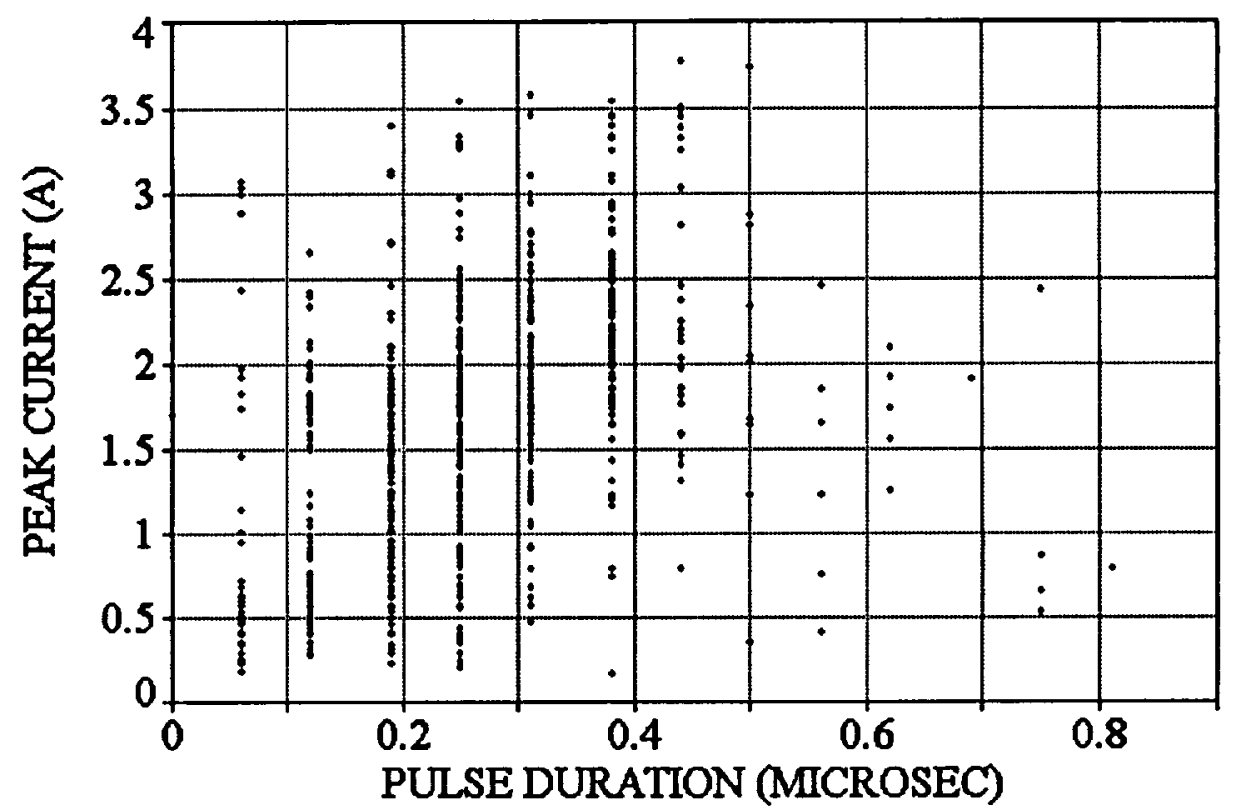

Fig. 8a. Data from the Experiment $\# 64-1$. The bias voltage $V=400 \mathrm{~V}$, and 750 arcs were registered.

\section{High-frequency longitudinal waves}

The equation for the Fourier transformation of the electrical field strength can be written within the framework of a high frequency approximation $\left(>>F_{H}, f_{L H}\right)$ in the following form:

$$
\begin{aligned}
& \sum_{j=1}^{3} f^{2}\left[P(f) \cdot b_{i} \cdot b_{j}+S(f) \cdot\left(\delta_{i j}-b_{i} \cdot b_{j}\right)-i \cdot D(f) \cdot \sum_{k=1}^{3} \varepsilon_{i j k} \cdot b_{k}\right] E_{j}\left(f, \kappa_{1}, \kappa_{2}, \kappa_{3}\right)-\kappa^{2} \cdot E_{i}\left(f, \kappa_{1}, \kappa_{2}, \kappa_{3}\right) \\
& +\kappa_{i} \cdot \sum_{j=1}^{3} \kappa_{j} \cdot E_{j}\left(f, \kappa_{1}, \kappa_{2}, \kappa_{3}\right)=-1.8 \cdot 10^{4} \cdot i \cdot f \cdot \Phi(f) \cdot a \cdot n_{i}
\end{aligned}
$$

where

$S(f)=\frac{f^{2}-f_{U H}^{2}}{f^{2}-F_{e}^{2}} ; \quad D(f)=-\frac{f_{e}^{2} \cdot F_{e}}{f \cdot\left(f^{2}-F_{e}^{2}\right)} ; \quad \kappa^{2}=c^{2} \cdot k^{2} ; \quad \mathbf{K}=\left(\kappa_{1}, \kappa_{2}, \kappa_{3}\right)$, 
and the electric field strength and frequency are expressed in the units $V m^{3} / m^{*} M H z$ and $M H z$ respectively.

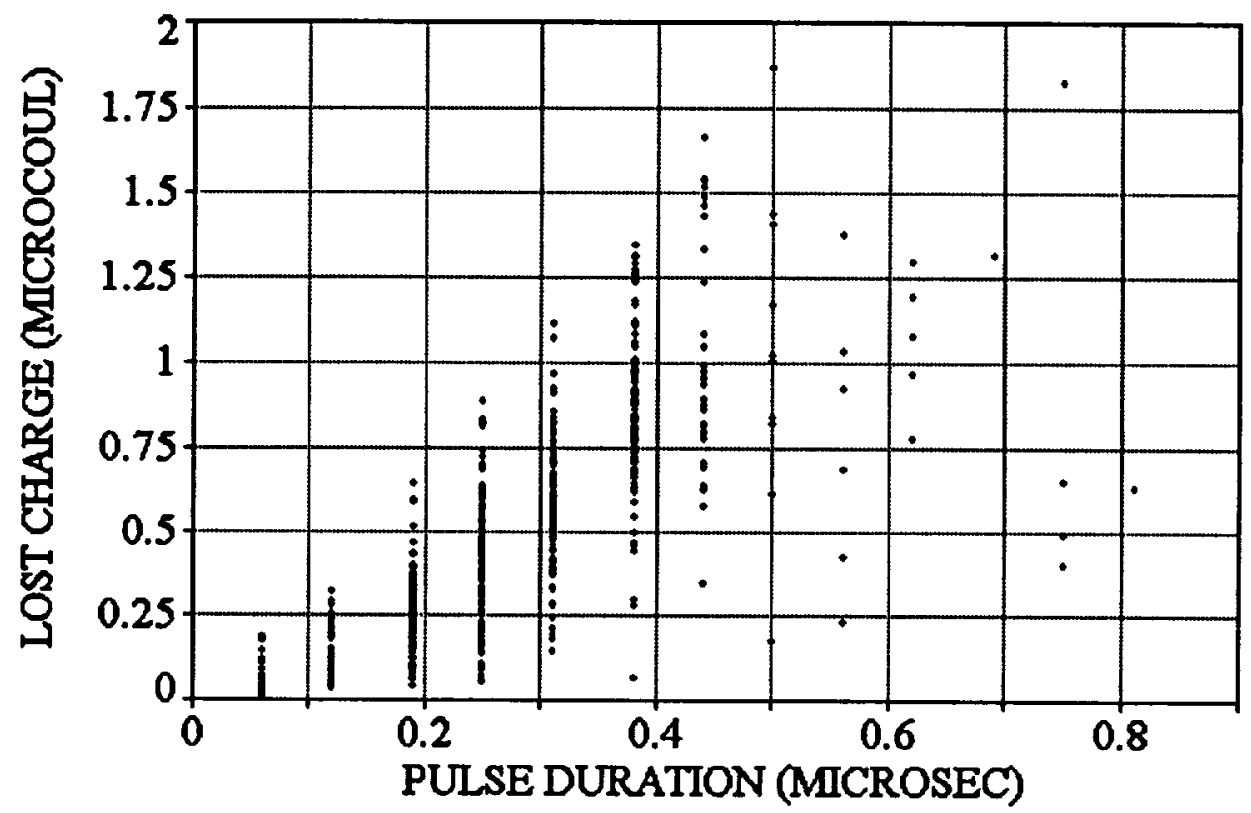

Fig.8b Lost charge vs. pulse duration for the same experiment. $A$ trend is clear (correlation coefficient $\operatorname{corr}(I, T)=0.427$ ).

The computations below are performed for the geometry shown in Fig. 9.

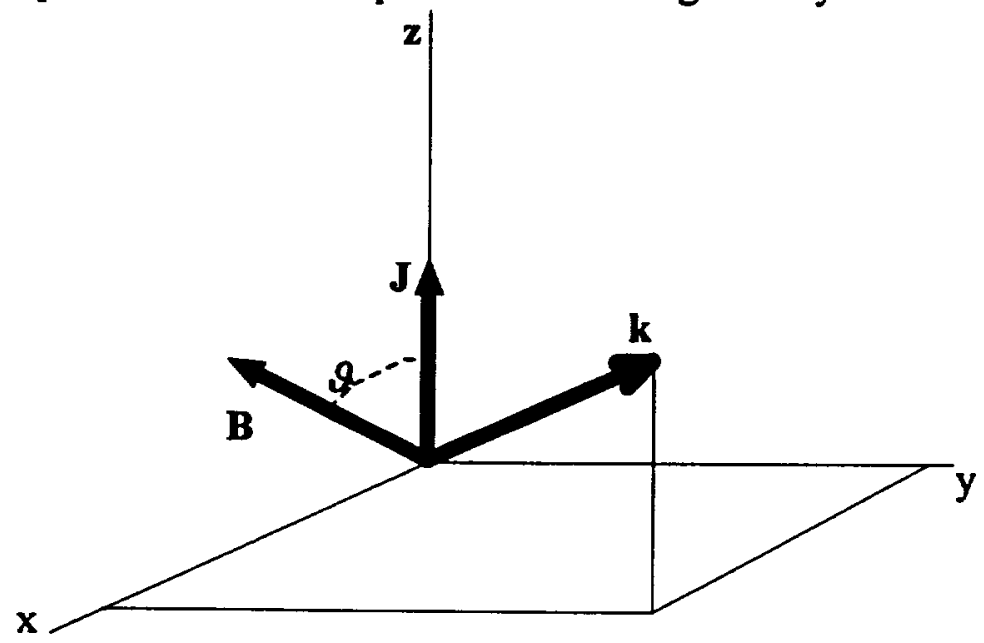

Fig. 9 The geometry that was used for computations described below. 
Table 1

exper

C, Imax, $\Delta t, \quad f \max , n_{0} / 10^{6} \quad U \max , \quad T_{\text {pules }} \Delta Q$,

\begin{tabular}{|c|c|c|c|c|c|c|c|c|}
\hline & $(\mu \mathrm{F})$ & (A) & $(\mu s)$ & $(\mathrm{MHz})$ & $\left(\mathrm{cm}^{-3}\right)$ & (V) & $(\mu s)$ & $(\mu \mathrm{Cl})$ \\
\hline LPA4 & 0.15 & 3.5 & 9 & 18 & 4 & 0.08 & 7 & 31.5 \\
\hline LPA5 & 0.15 & 3 & 10 & 18 & 4 & 0.02 & 5 & 30 \\
\hline LPBS & 0.15 & 1.2 & 15 & 15 & 3 & 0.3 & 10 & 18 \\
\hline LPA7 & 0.15 & 3 & 10 & & & 0.03 & 10 & 30 \\
\hline LPB6 & 0.15 & 2.5 & 12 & 12 & 1.5 & 0.12 & 7 & 30 \\
\hline LPB7 & 0.15 & 2.5 & 15 & 10 & 1.2 & 0.08 & 10 & 37.5 \\
\hline LPA8 & 0.15 & 3 & 10 & 20 & 5 & 0.03 & 10 & 30 \\
\hline LPB8 & 0.15 & 2.7 & 10 & 15 & 3 & 0.06 & 10 & 27 \\
\hline LPA9 & 0.15 & 3 & 12 & 18 & 4 & 0.03 & 7 & 36 \\
\hline LPB9 & 0.15 & 2 & 13 & 10 & 1.2 & 0.2 & 8 & 26 \\
\hline LPB10 & 0.15 & 2.8 & 10 & 14 & 2.4 & 0.1 & 7 & 28 \\
\hline DLPA2 & 0.5 & 12 & 10 & 17 & 3.5 & 0.2 & 7 & 120 \\
\hline DLPA3 & 0.5 & 7 & 17 & 16 & 3 & 0.22 & 8 & 119 \\
\hline DLPA8 & 0.5 & 13 & 8 & 20 & 5 & 0.05 & 5 & 104 \\
\hline DLPB8 & 0.5 & 14 & 8 & 15 & 3 & 0.3 & 7 & 112 \\
\hline DLPB2 & 0.5 & 8.2 & 15 & 12 & 1.6 & 0.75 & 15 & 123 \\
\hline DLPB4 & 0.5 & 9 & 13 & 11 & 1.4 & 0.5 & 14 & 117 \\
\hline DLPC8 & 0.5 & 9 & 13 & 12 & 1.6 & 0.15 & 10 & 117 \\
\hline DLPC4 & 0.5 & 13 & 8 & 6 & 0.7 & 0.03 & 10 & 104 \\
\hline DLPC2 & 0.5 & 8.2 & 13 & 14 & 2.4 & 0.15 & 10 & 107 \\
\hline ELPA2 & 0.22 & 2.5 & 12 & 15 & 3 & 0.05 & 7 & 30 \\
\hline ELPA3 & 0.22 & 2.8 & 12 & 15 & 3 & 0.06 & 8 & 33.6 \\
\hline ELPA 4 & 0.22 & 3.6 & 10 & 22 & 6 & 0.05 & 8 & 36 \\
\hline ELPA5 & 0.22 & 4.1 & 10 & 17 & 5 & 0.18 & 5 & 41 \\
\hline ELPA6 & 0.22 & 3.8 & 9 & 10 & 1.2 & 0.02 & 10 & 34.2 \\
\hline ELPB1 & 0.22 & 3.3 & 9.5 & 9 & 1 & 0.3 & 8 & 31.4 \\
\hline ELPB4 & 0.22 & 2.5 & 14 & 10 & 1.2 & 0.35 & 10 & 35 \\
\hline ELPB5 & 0.22 & 4.3 & 9.1 & 9 & 1 & 0.75 & 30 & 39.1 \\
\hline ELPC1 & 0.22 & 3.1 & 13.6 & 5 & 0.2 & 0.02 & 5 & 42.2 \\
\hline ELPC2 & 0.22 & 2.6 & 12 & 8.8 & 1 & 0.45 & 10 & 31.2 \\
\hline ELPC3 & 0.22 & 2.2 & 16 & 9 & 1 & 0.6 & 13 & 35.2 \\
\hline ELPC4 & 0.22 & 2 & 16 & 13 & 2 & 0.075 & 12 & 32 \\
\hline ELPC5 & 0.22 & 4.1 & 10 & 9 & 1 & 0.02 & 10 & 41 \\
\hline ELPC6 & 0.22 & 2.3 & 13 & 12 & 1.6 & 0.1 & 8 & 30 \\
\hline \multicolumn{2}{|c|}{$\begin{array}{l}\operatorname{corr}(\operatorname{Imax}, \text { Umax }) \\
0.1126199\end{array}$} & \multicolumn{2}{|c|}{$\begin{array}{l}\operatorname{corr}(C, \Delta Q) \\
0.9791811\end{array}$} & \multicolumn{2}{|c|}{$\begin{array}{l}\operatorname{corr}(U \max , \Delta Q) \\
0.2534364\end{array}$} & $\begin{array}{l}\operatorname{corr}\left(n_{0}, \Delta Q\right) \\
-0.001009\end{array}$ & \multicolumn{2}{|c|}{$\begin{array}{c}\operatorname{corr}\left(\Delta t, T_{\text {pulao }}\right) \\
0.096377\end{array}$} \\
\hline
\end{tabular}

B-probe

$\begin{array}{lllllll}\text { Imax } & \Delta t & \mathrm{n}_{0} & \mathrm{Umax} & \mathrm{T}_{\text {pula }} & \Delta \mathrm{Q} & \mathrm{A}\left(\mathrm{f}_{\max }\right) \\ 1.2 & 15 & 3 & 0.3 & 10 & 18 & 72 \\ 2.5 & 12 & 1.5 & 0.12 & 7 & 30 & 31 \\ 2.5 & 15 & 1.2 & 0.08 & 10 & 37.5 & 36 \\ 2.7 & 10 & 3 & 0.06 & 10 & 27 & 54.5 \\ 2 & 13 & 1.2 & 0.2 & 8 & 26 & 62 \\ 2.8 & 10 & 2.4 & 0.1 & 7 & 28 & 55 \\ 14 & 8 & 3 & 0.3 & 7 & 112 & 26 \\ 8.2 & 15 & 1.6 & 0.75 & 15 & 123 & 130 \\ 9 & 13 & 1.4 & 0.5 & 14 & 117 & 55 \\ 3.3 & 9.5 & 1 & 0.3 & 8 & 31.4 & 20 \\ 2.5 & 14 & 1.2 & 0.35 & 10 & 35 & 25 \\ 4.3 & 9.1 & 1 & 0.75 & 30 & 39.1 & 68\end{array}$


The correlational characteristics do not change significantly if we take into account data from one probe. This is seen in the row of numbers that are calculated for $B$ probe only: $\begin{array}{lllll}\operatorname{corr}(\operatorname{Imax}, U \operatorname{Umax}) & \operatorname{corr}\left(\Delta t, \mathrm{~T}_{\text {pulmo }}\right) & \operatorname{corr}\left(\mathrm{n}_{\mathrm{o}}, \Delta Q\right) & \operatorname{corr}\left(\mathrm{I}_{\max }, \mathrm{A}\left(\mathrm{f}_{\max }\right)\right) & \operatorname{corr}\left(\mathrm{U}_{\max }, \mathrm{A}\left(\mathrm{f}_{\max }\right)\right) \\ 0.414447 & -0.096776 & 0.0405188 & 0.0921994 & 0.5849428\end{array}$

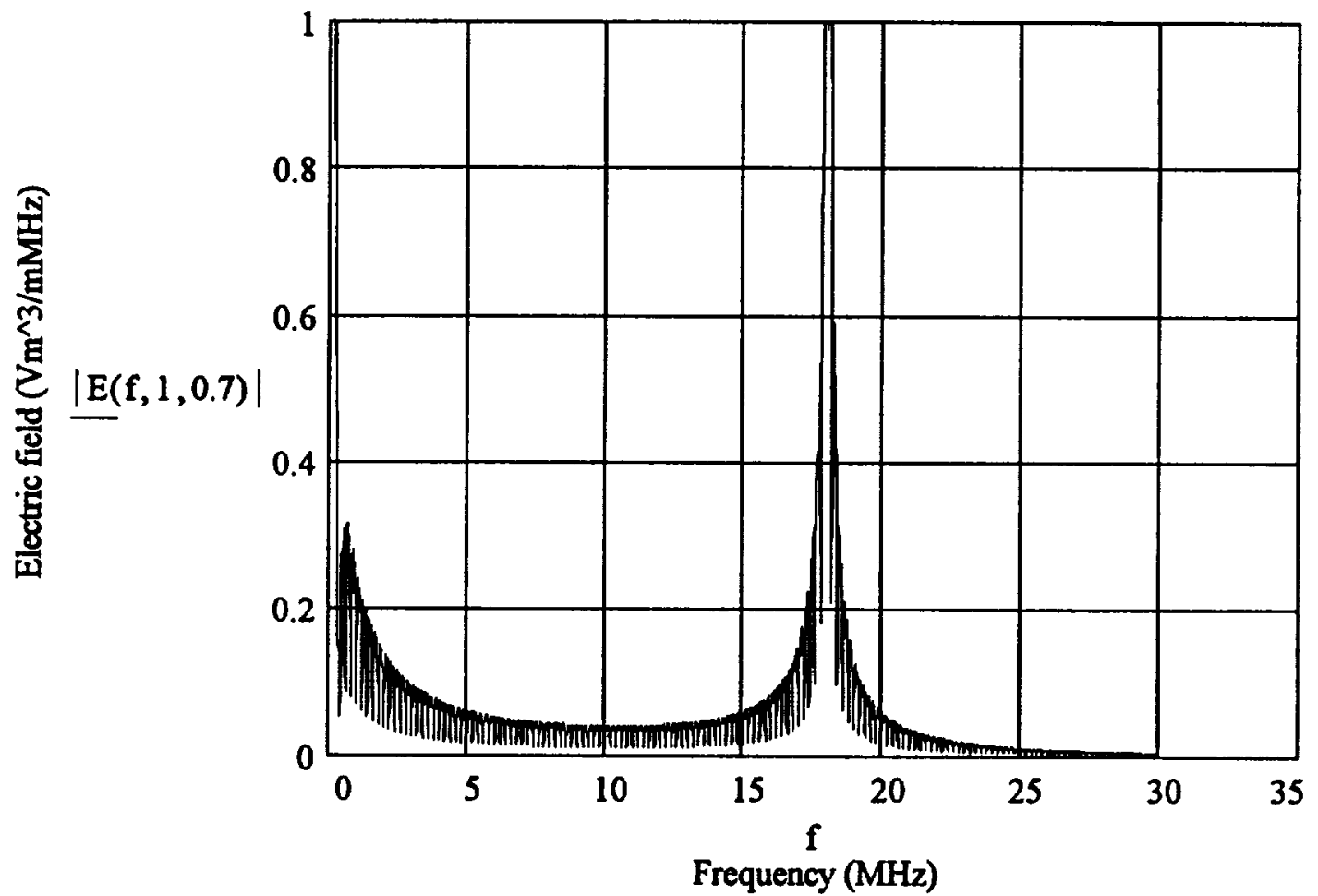

Fig.10a The electric field strength derived from Eq.17. The resonance at the plasma frequency $\left(f_{e}=18 \mathrm{MHz}\right)$ is very strong for long longitudinal waves $(K=1)$ travelling along the magnetic field. $\left(F_{e}=0.5 \mathrm{MHz}, \vartheta=45^{\circ}\right.$, and the attenuation rate $\left.\gamma / f=0.03\right)$

Now we have theoretical results that demonstrate the general features of plasma waves generated by arcing on the conductive plate immersed in a low density plasma, and we can compare experimental data with theoretical predictions. The results of one experiment are shown in Fig. 11.

We may conclude that there is a quite good agreement between theoretical calculations (Fig. 10) and experimental data (Fig. 11d) concerning the spectrum of plasma waves.

To understand the origin of the second pulse in Fig. $11 \mathrm{c}$ we computed the spectrogram of fluctuations for this paricular experiment (Fig. 12). One can see that the frequencies of plasma oscillations during the first pulse lie in the range $10-12 \mathrm{MHz}$, and these frequencies increase up to $22 \mathrm{MHz}$ during the second pulse (80-100 $\mu$ s). If we suggest 


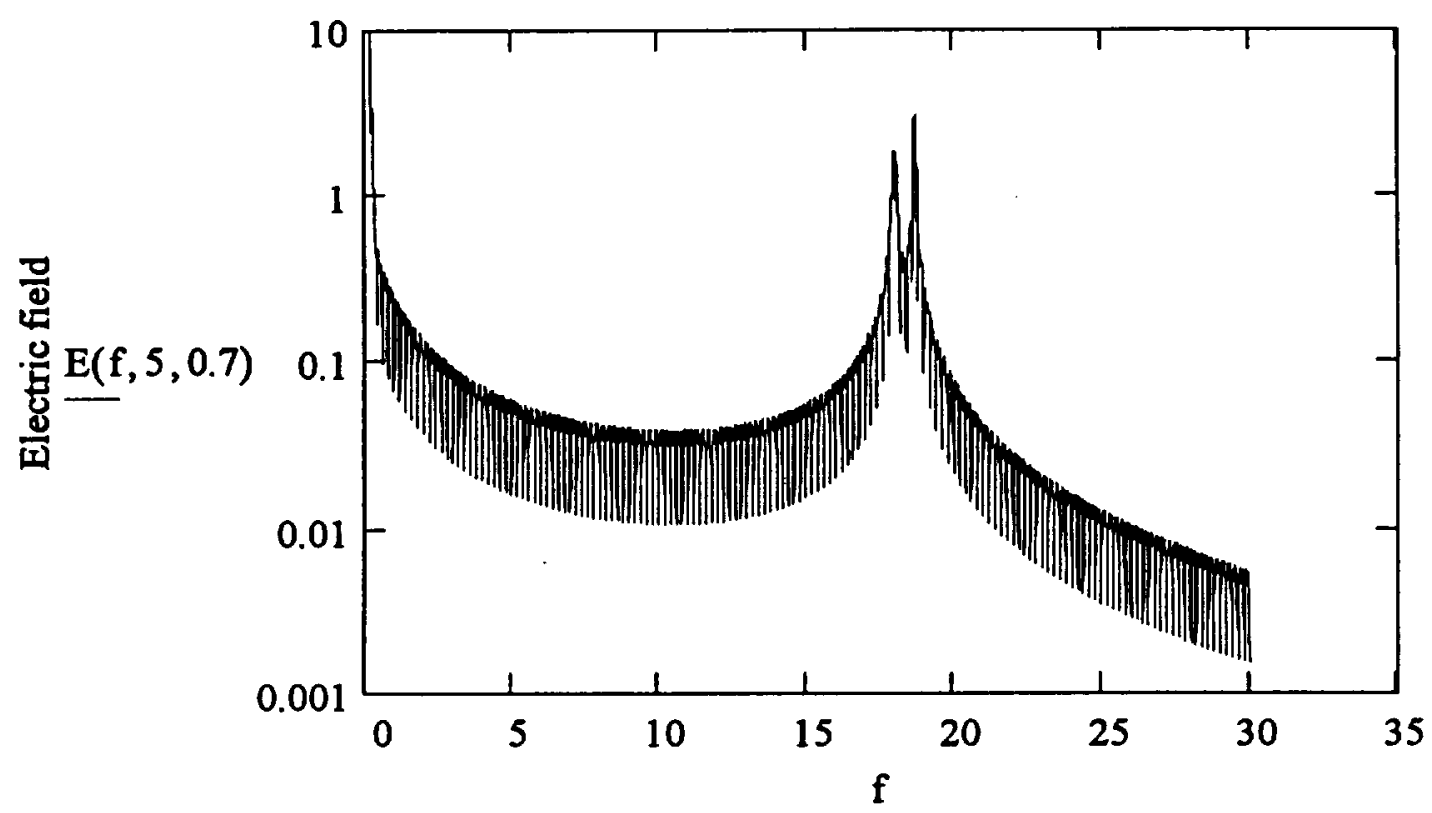

Frequency (MHz)

Fig. 10b. The electric field strength derived from Eq. 17 for longitudinal plasma waves traveling perpendicularly to the magnetic field. $\left(F_{\mathrm{e}}=0.5 \mathrm{MHz}, \vartheta=45^{\circ}, k=5\right.$, and $\left.\gamma / f_{\mathrm{e}}=0.03\right)$. The splitting of the maximum at the plasma frequency is seen very clearly.

that Langmuir waves were registered in this experiment, the changes in the frequencies of oscillation should mean a considerable increase of the electron number density - from (1.2-1.8) $10^{6}$ up to $6 \cdot 10^{6} \mathrm{~cm}^{-3}$. This growth could be explained by the expanding arc plasma front that intersected the Langmuir probe. ${ }^{18}$ Moreover, because the time interval between the two pulses is approximately equal to $25 \mu$ s (Fig. 11c), and the distance between LP and arc site is equal to $L=75 \mathrm{~cm}$, we can calculate the speed of the plasma front $f=\frac{L}{\Delta \tau} \approx 30 \mathrm{~km} / \mathrm{s}$. This estimate for front velocity derived from our experimental data is in good agreement with the direct measurements ${ }^{18}$ performed in a plasma with almost the same parameters as in our experiment. But the absence of correlations between the frequencies of oscillations and the magnitudes of lost electrical charges that were determined for the second pulses in a set of experiments does not allow us to be absolutely sure of the adequacy of this simple model. 


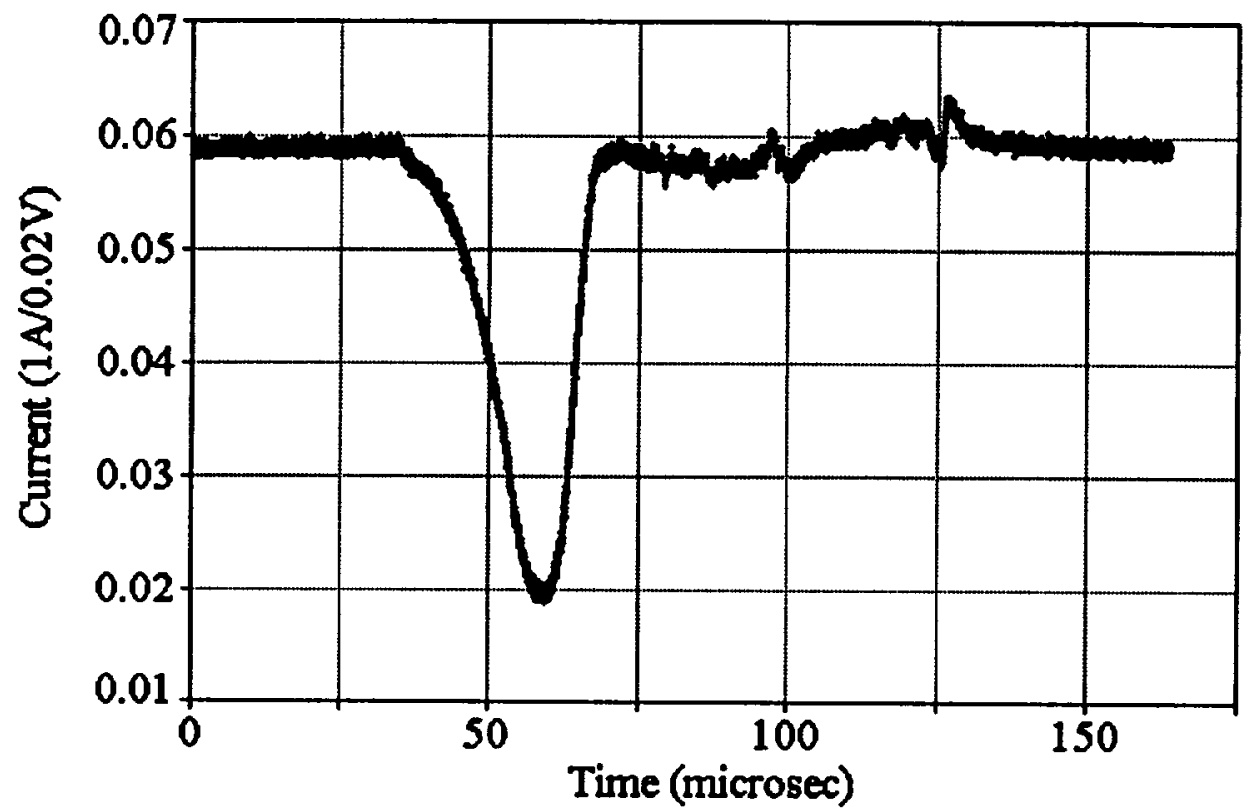

Fig. 11a. Experiment LPB_9. The additional capacitance is equal to $0.15 \mu \mathrm{F}$, and the amplitude of current is equal to $2 \mathrm{~A}$.

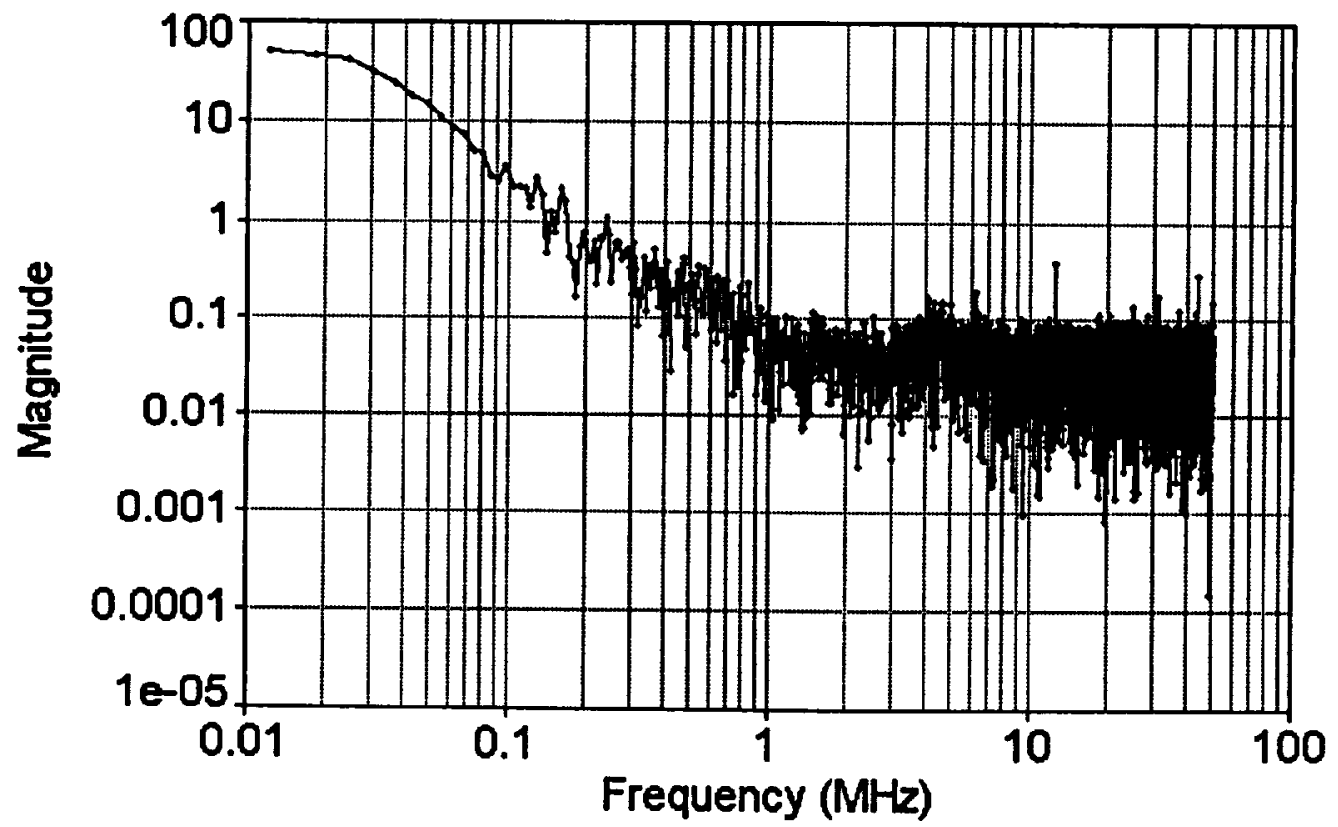

Fig. 11b. The spectrum of the arc current pulse shown above. 


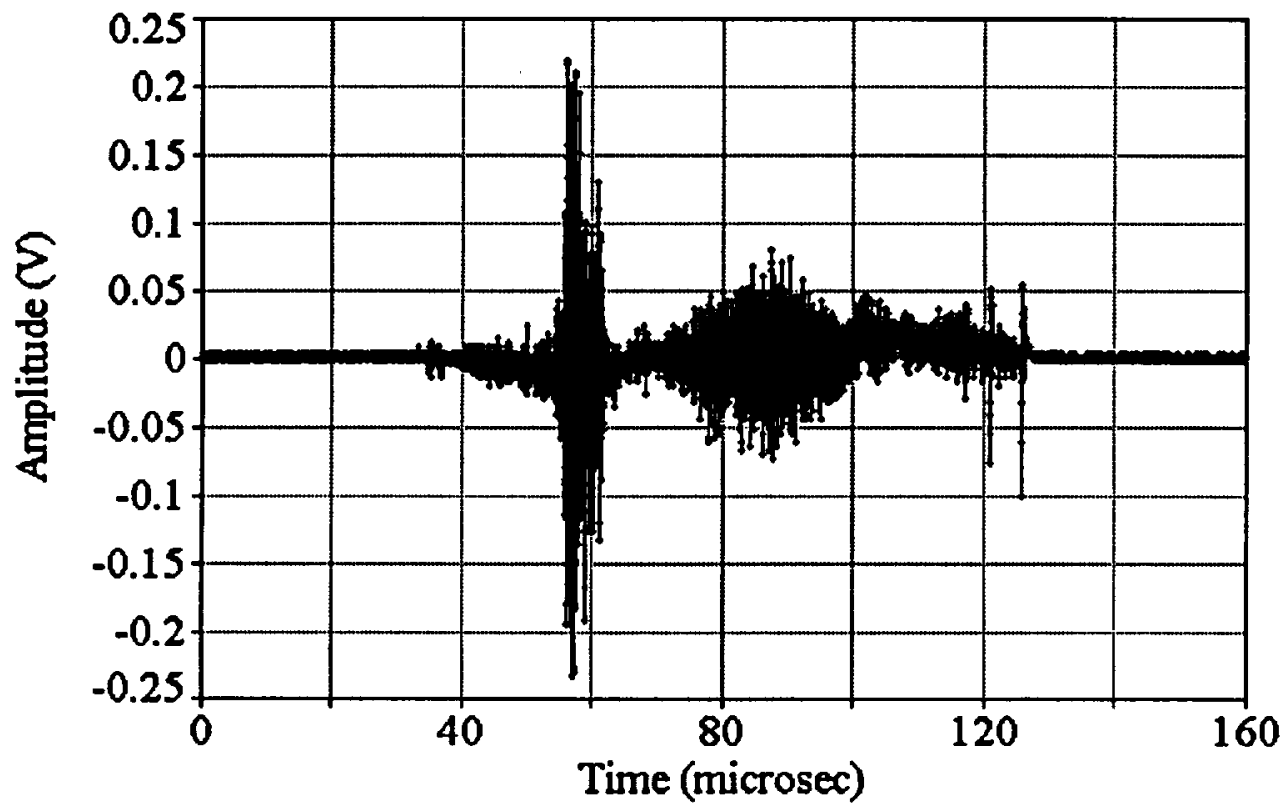

Fig. 11c. The Langmuir probe potential fluctuations. Two separated pulses are seen quite clear. The first pulse has the highest amplitude, and its maximum is simultaneous to the maximum of the arc current pulse.

The amplitude of the electron number density fluctuations can be estimated from the obvious relation:

$$
\eta=\frac{\delta n_{e}}{n_{e}}=\frac{U_{\max }}{T_{.}} \approx 0.02-0.75
$$

To obtain the estimate (18) we used data from the Table 1 for $U_{\max }$ and measurements of the electron temperature which indicated the magnitude $T_{e} \approx 1 \mathrm{eV}$. It is much more difficult to obtain information regarding the wave numbers of observed waves. Really, the LP provides measurements that represent the fluctuations of electrostatic potential integrated over wavenumbers:

$$
U(f)=\int U(f, k) \cdot d^{3} k
$$




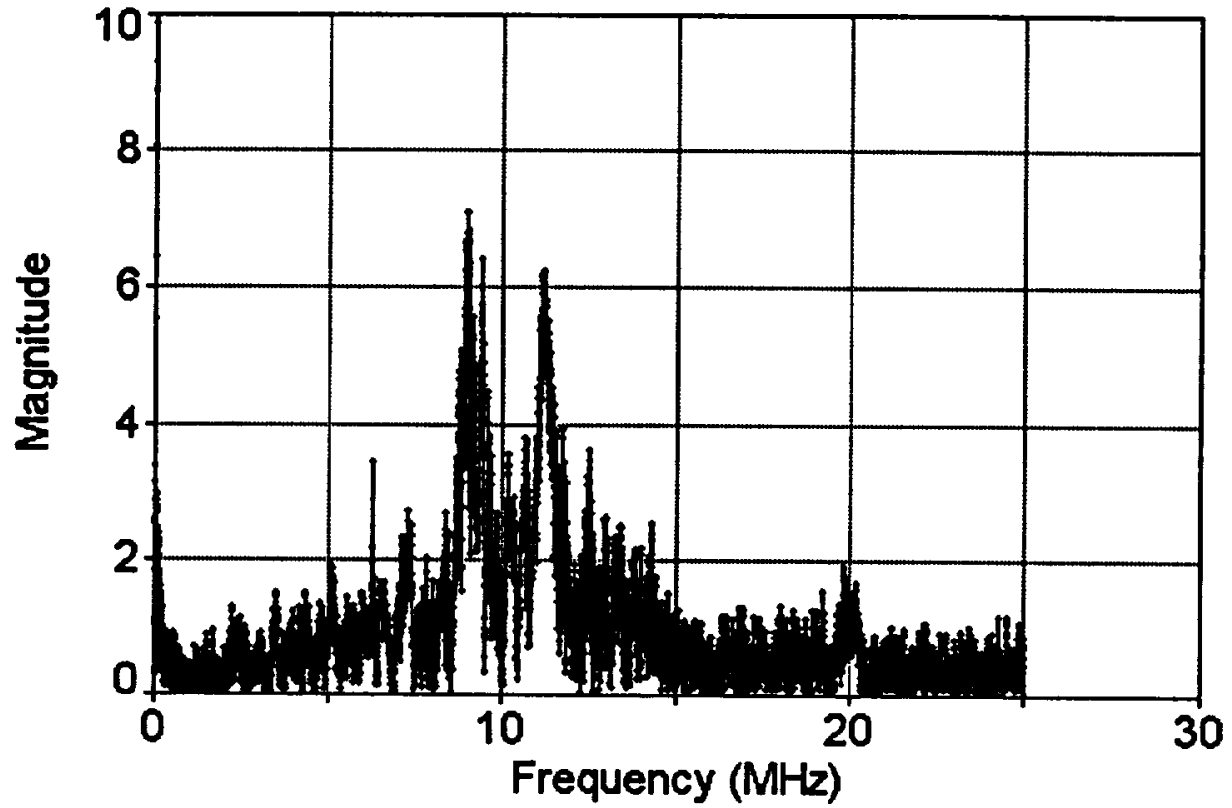

Fig.11d. Spectrum of fuctuations shown above. Resonance at plasma frequency can be easily observed.

Thus, we may determine the range of wave numbers only but not the spectral density of fluctuations $U(f, k)$ itself. The upper limit can be estimated from the formula for Landau damping of plasma waves. According to Ref.(13) the ratio of decrement to the plasma frequency can be written in the following form:

$$
\frac{\gamma}{f .}=G(x)=2 \pi \cdot\left(\frac{\pi}{8}\right)^{1 / 2} \cdot x^{-3} \cdot \exp \left(-\frac{3}{2}-\frac{1}{2 \cdot x^{2}}\right.
$$

where $x=k \cdot \Lambda$.

It seems convenient for further analysis to represent Eq. (20) in the graph (Fig. 13). If we suggest that Landau damping is the only mechanism for the attenuation of plasma waves, we can estimate the decrement as $G(x) \leq 0.01$ from the data shown in Fig. 1lc. 


\section{LPB_9 $(5,000-13,000)$}

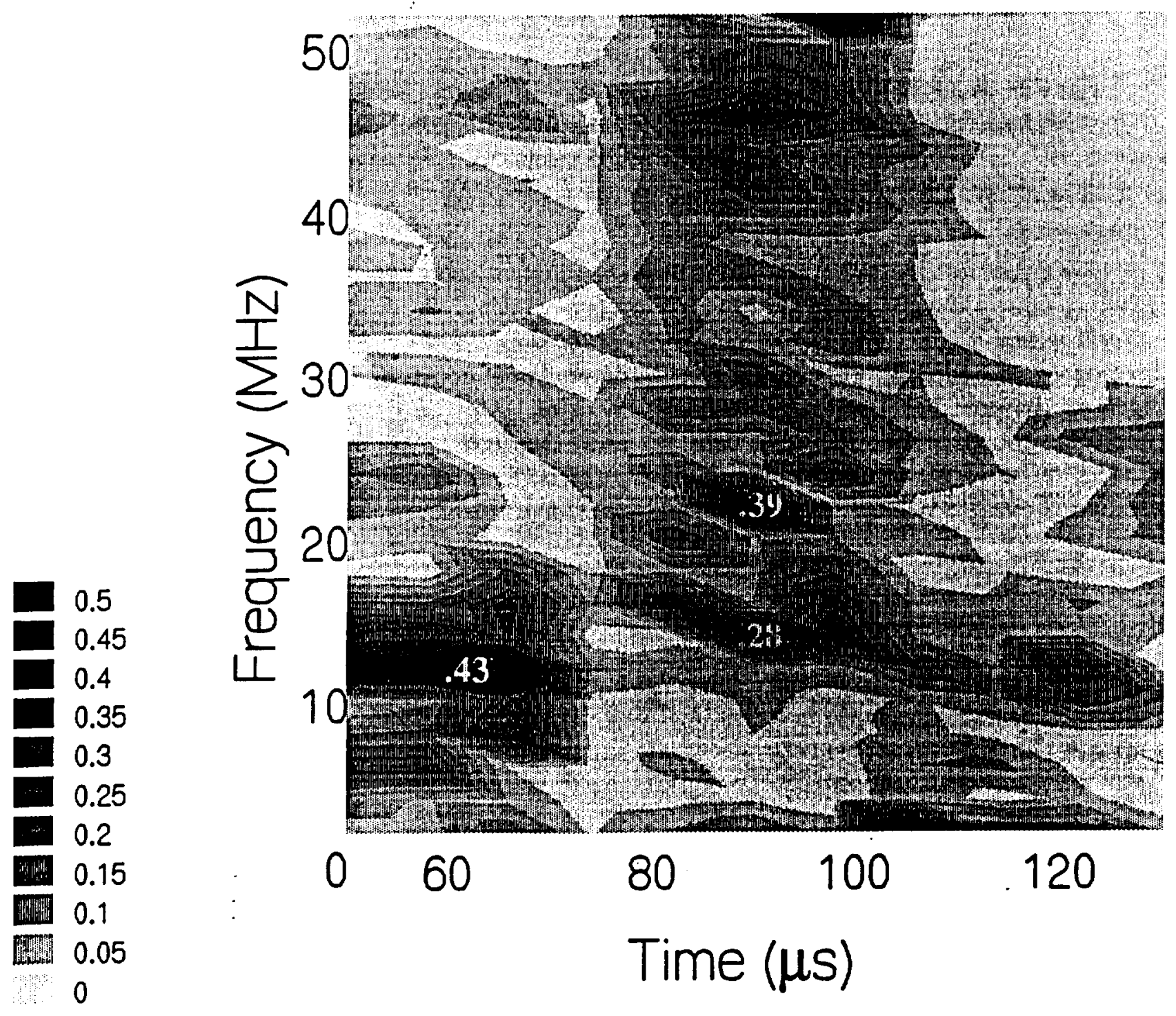

Fig. 12. The spectrogram of the experiment LPB_9. Changes in plasma frequency are seen very well. 
This means that $x \leq 0.2$ (Fig. 13), and the lower limit on the wave length $\lambda_{\min }=10 \cdot \pi \cdot \Lambda$.

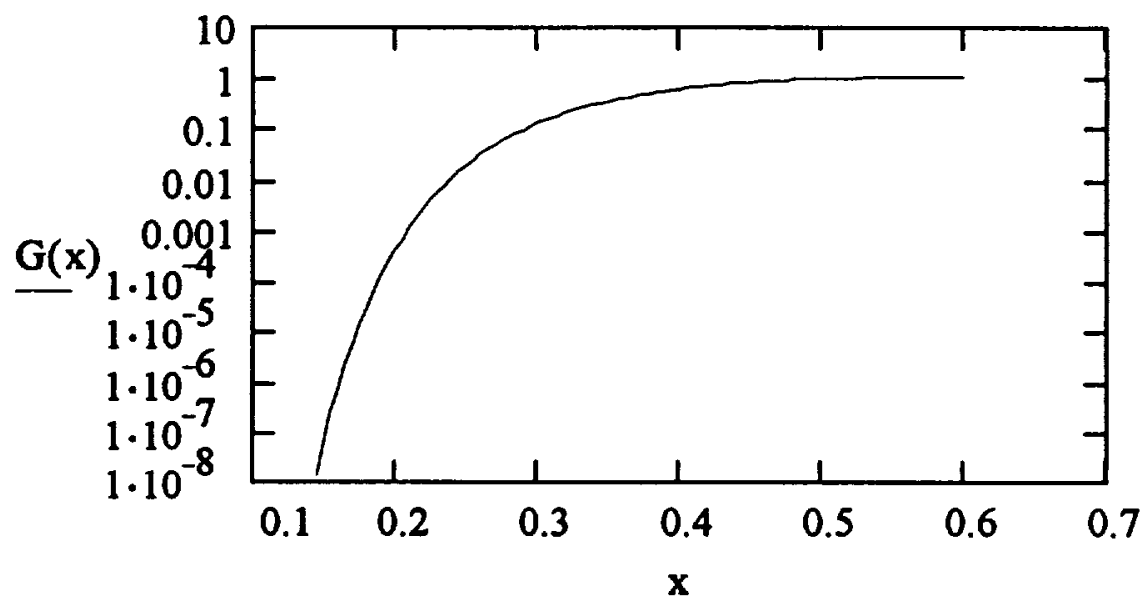

Fig. 13 . Attenuation rate vs. wave number for plasma waves.

For example, during the experiment LPB_9 the electron number density was equal to $n_{c}=10^{6} \mathrm{~cm}^{-3} \quad$. The Debye length can be easily calculated : $\Lambda_{c}=0.6 \mathrm{~cm}$; thus, we get the lower limit on the length of plasma waves $\lambda_{\min }=18 \mathrm{~cm}$ The phase speed of electrostatic waves $V_{p}=\lambda \cdot f$ exceeds $2 \cdot 10^{8} \mathrm{~cm} / \mathrm{s}$; thus, we did not have any chance to register a time delay in the pulse arrival time even if we were performing measurements for two or three probes simultaneously.

As it is seen from Table 1 , the amplitude of fluctuations was very high for several experiments: $U_{\max }>0.3 \mathrm{~V}$. We may expect that nonlinear conversion of plasma waves influences the time behaviour of pulses in such cases. One of the possible nonlinear processes is the generation of ion acoustic waves by the decay instability. ${ }^{20}$ This process has the threshold - the critical magnitude of the electric field strength, shown in Fig. 14 for different electron number densities and electron temperatures.

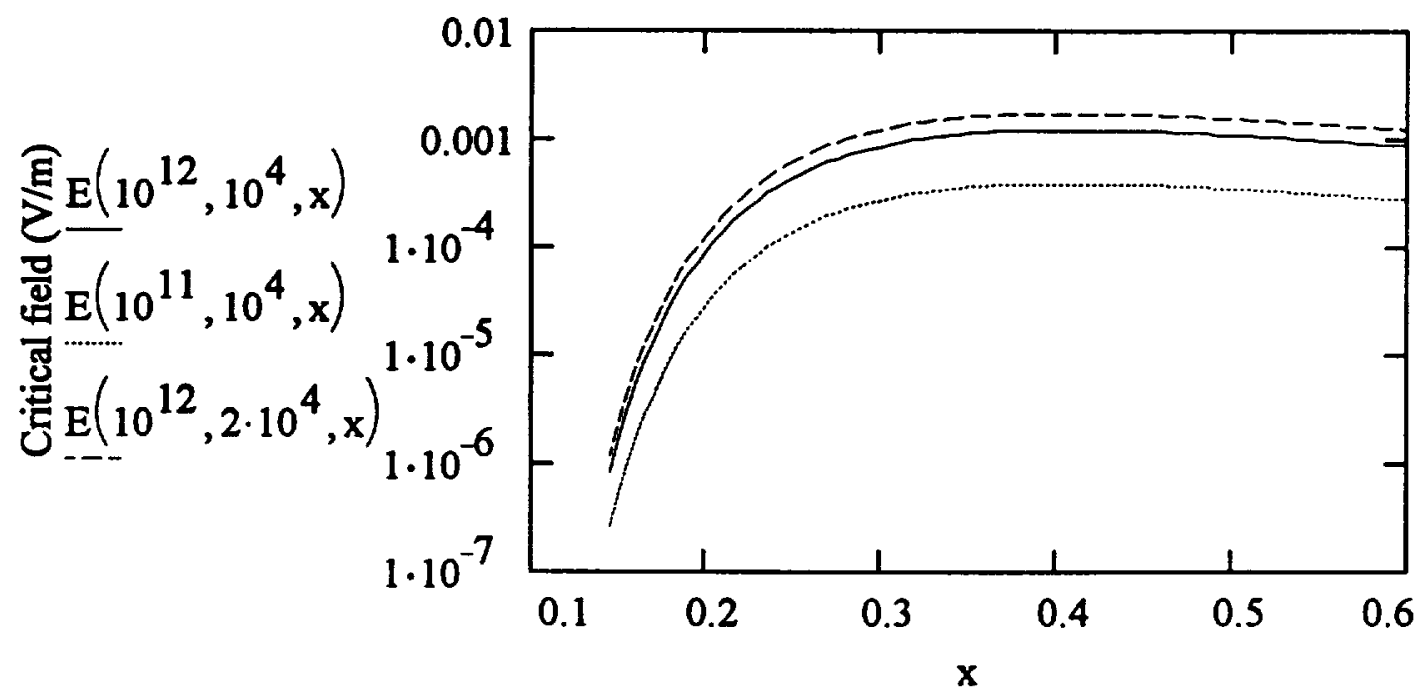

Fig. 14. Critical electric field strength vs. dimensionless wavenumber for two electron number densities $n_{e}=10^{11}$ and $10^{12} \mathrm{~m}^{3}$ and for two electron temperatures $T_{c}=10^{4}$ and $2 \cdot 10^{4} \mathrm{~K}$. 


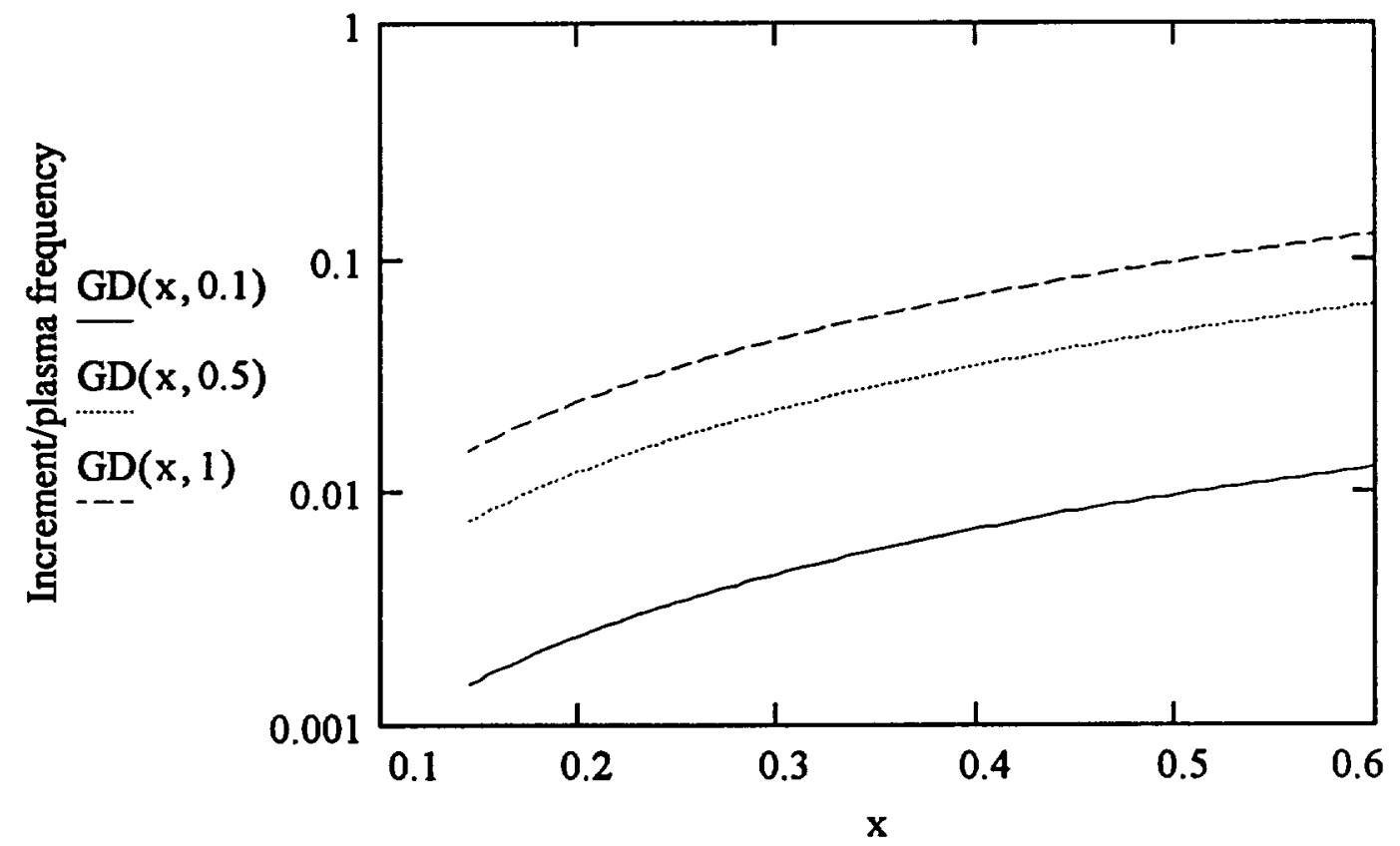

Fig. 15. Increment of plasma waves damping due to nonlinear conversion for three magnitudes of potential $\eta=0.1,0.5$ and 1 .

One can see in the graph above that the increment of nonlinear conversion becomes as large as the increment of Landau damping for waves long enough $(x \leq 0.2)$ when the amplitude of fluctuations exceeds $\eta_{c r}=0.5$. However, ion acoustic waves could not be registered even during three experiments with the largest amplitudes of fluctuation (DLPB_2, DLPB_4, and ELPB_5) because of the low frequency of such waves (a few $\mathrm{kHz}$ ). We might suggest that some nonlinear processes took place in the plasma during the experiments with the highest level of fluctuations. Such nonlinear processes should cause a widening of the resonance curve at the plasma frequency and the generation of additional broadband noise, and these expectations are confirmed by measurements (see Fig. 16). On the contrary, experiments with low level of fluctuations demonstrate very narrow resonance at the plasma frequency (one example is shown in Fig. 17).

Now we can estimate the amplitude of electric field strength for longitudinal plasma waves:

$E_{\max }=k \cdot U_{\max }=\frac{2 \cdot \pi \cdot U_{\max }}{\lambda}$

During the experiment ELPB_5, $U_{\max }=0.75 \mathrm{~V}$ and $\lambda_{\min }=0.2 \mathrm{~m}$; thus, we obtain an upper limit on the electric field strength $E_{\max }=24 \mathrm{~V} / \mathrm{m}$. This is a very rough estimate because each experiment demonstrates a complicated spectral distribution of fluctuations. For the experiment DLPA_3, we estimate the spectral density of electric field as $E(\hbar) \sim 1$ $\mathrm{V} / \mathrm{m} \cdot \mathrm{MHz}$ in the vicinity of the resonance (Fig. 17). 


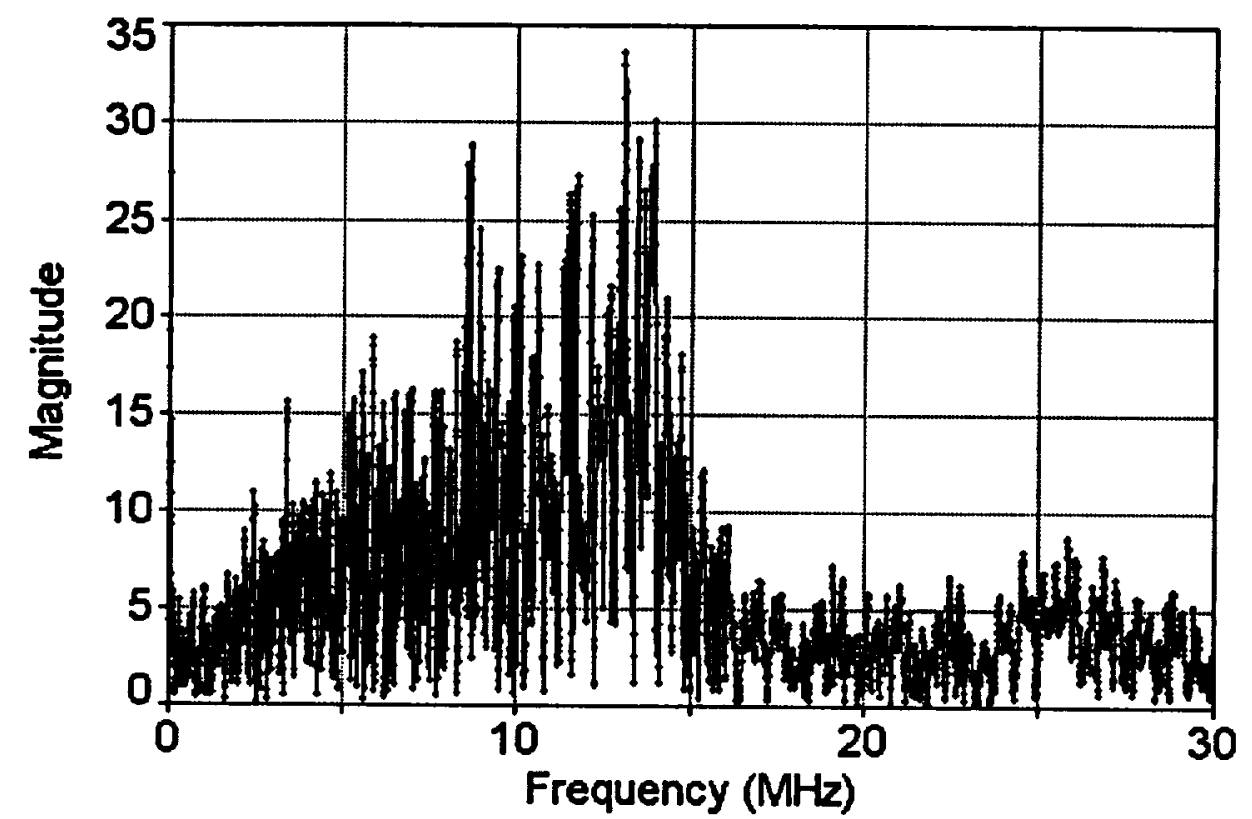

Fig. 16. Experiment ELPB_5. Spectrum of fluctuations differs significantly from one in Fig. 11d perhaps because of nonlinear processes developed in the plasma with a high level of fluctuations.

\section{Conclusion}

One of the most important problems facing large spacecraft with powerful high voltage solar arrays is the generation of electromagnetic radiation by arcing on its surfaces. As it follows from our calculations and available experimental data, broadband electromagnetic noise with electric field amplitudes as high as a few volts per meter can be generated by arcing. To prevent a negative influence of this radiation on spacecraft operation additional work should be done: i)to establish technical requirements on equipment and devices that could be influenced; ii)to determine the spectrum and level of radiation that could be expected in the vicinity of the equipment; iii)to elaborate methods for mitigating adverse consequences.

\section{ACKNOWLEDGMENTS}

This work was performed while B. Vayner held a National Research CouncilNASA/LeRC Research Associateship. 


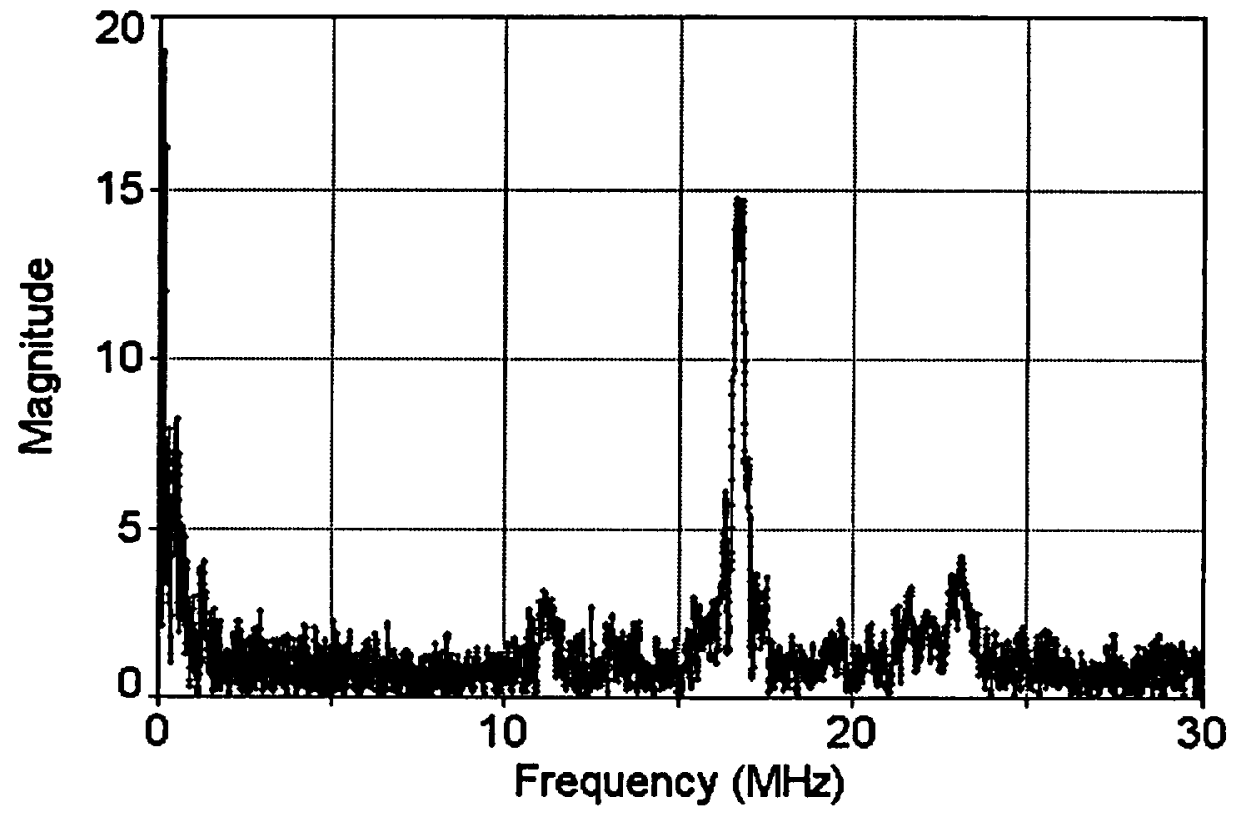

Fig. 17. Experiment DLPA_3. Amplitude of fluctuations is relatively low $(\eta=0.2)$, and spectrum demonstrates a narrow resonance at the plasma frequency.

\section{References}

'Snyder, D.B. Characteristics of Arc Currents on a Negatively Biased Solar Cell Array in a Plasma. NASA TM-83728, 1985

${ }^{2}$ Ferguson, D. The Voltage Threshold for Arcing for Solar Cells in LEO-Flight and Ground Test Results. Proc. 24th AIAA Aerospace Sci. Meeting, Reno, Nevada, 1986

${ }^{3}$ Upschulte, B.L., Marinelli, W.J., Carleton, K.L., Weyl, G., Aifer, E., and Hastings, D.E. Arcing of Negatively Biased Solar Cells in a Plasma Environment, Journal of Spacecraft and Rockets, Vol. 31, No 3, 1994, pp. 493-501

${ }^{4}$ Ferguson, D.C., and Hillard, G.B., "Preliminary Results From the Flight of the Solar Array Module Plasma Interactions Experiment (SAMPIE)", Proceedings of the XIII Space Photovoltaic Research and Technology Conference, NASA CP-3278, June, 1994, pp.247-251.

${ }^{5}$ Leung, P. Charging/Discharging Characteristics of Spacesuit Materials, Final Report JPL D$3483,1986,18 \mathrm{p}$.

${ }^{6}$ Purvis., C.K., Ferguson, D.C., Snyder, D.B., Grier, N.T., Staskus, J.V., and Roche, J.C. Environmental Interactions Considerations for Space Station and Solar Array Design. (Preliminary Document), NASA/LeRC, Internal Report, 1986, 51 p.

${ }^{7}$ Hastings, D.E. A Review of Plasma Interactions with Spacecraft in Low Earth Orbit. Journal ofGeophysical Research, Vol. 100, No.A8, 1995 , p.14,547-14,483.

${ }^{8}$ Hillard, G.B., and Ferguson, D.C., "Solar Array Module Plasma Interactions Experiment (SAMPIE): Science and Technology Objectives", Journal of Spacecraft and Rockets, Vol.30, 1993, pp.488-494. 
${ }^{9}$ Kuninaka, H. Space Experiment on Plasma Interaction Caused by High Voltage Photovoltaic Power Generation. Journal of Spacecraft and Rockets, Vol. 32, No.5, 1995, pp. 894-898.

${ }^{10}$ Vayner, B.V. , and Ferguson, D.C. Low Frequency Waves in the Plasma Environment Around the Shuttle. Journal of Spacecraft and Rockets, Vol. 33, No.2, 1996

${ }^{11}$ Doreswamy, C.V., Vayner, B.V., Ferguson, D.C., Snyder, D.B., and Galofaro, J.T. A

Dynamical Analysis of the High Frequency Plasma Waves Generated by Arcing on an Anodized Conductive Plate. AIAA Paper No. 1996

${ }^{12}$ Barnett, A., and Olbert, S. Radiation of Plasma Waves by a Conducting Body Moving Trough a Magnetized Plasma, Journal of Geophysical Research, Vol.91, No A9, 1986, pp.10,117-10,335.

${ }^{13}$ Akhiezer, A.I., Akhiezer, I.A., Polovin, R.V., Sitenko, A.G., and Stepanov, K.N., Electrodynamics of Plasma, 1st ed., Nauka, Moscow, 1974.

${ }^{14}$ Alpert, Ya.L. Space Plasma, Vol.1, Cambridge University Press, Cambridge, 1990, 308 p.

${ }^{15}$ Hastings, D.E., Weyl, G., and Kaufman, D. Threshold Voltage for Arcing on Negatively Biased Solar Arrays. Journal of Spacecraft and Rockets, Vol. 27, No. 5, 1990, pp. 539-544.

${ }^{16}$ Cho, M., and Hastings, D.E. Computer Particle Simulation of High Voltage Solar Array Arcing Onset. Journal of Spacecraft and Rockets, Vol. 30, No.2, 1993, pp.189-201

${ }^{17}$ Leung, P. Characterization of EMI Generated by the Discharge of a "VOLT" Solar Array, Final Report JPL D-2644, 1985, 17 p.

${ }^{18}$ Vaughn, J.A., Carruth Jr, M.R., Katz, I., Mandell, M.J., and Jongeward, G.A. Electrical Breakdown Currents on Large Spacecraft in Low Earth Orbit, Journal of Spacecraft and Rockets, Vol. 31, No.1, 1994, pp. 54-59.

${ }^{19}$ King, R.W.P., Smith, G.S., Owens, M., and Wu, T.T. Antennas in Matter, The MIT Press, Cambridge, MA, 1981, 868 p.

${ }^{20}$ Oraevskii, V.N., and Sagdeev, R.Z. Stability of Steady-State Longitudinal Plasma Oscillations. Soviet Physics-Technical Physics, Vol. 7, No. 11, 1963, pp.955-958. 



\begin{tabular}{|c|c|c|c|}
\hline \multicolumn{3}{|c|}{ REPORT DOCUMENTATION PAGE } & $\begin{array}{l}\text { Form Approved } \\
\text { OMB No. 0704-0188 }\end{array}$ \\
\hline \multicolumn{4}{|c|}{ 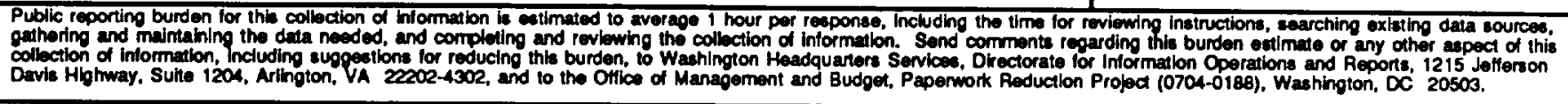 } \\
\hline 1. AGENCY USE ONLY (Leave blank) & \begin{tabular}{|} 
2. REPOAT DATE \\
May 1996
\end{tabular} & \multicolumn{2}{|c|}{$\begin{array}{l}\text { 3. REPOAT TYPE AND DATES COVERED } \\
\text { Technical Memorandum }\end{array}$} \\
\hline \multicolumn{3}{|c|}{$\begin{array}{l}\text { 4. ITRE AND SUBTILE } \\
\text { Electromagnetic Radiation Generated by Arcing in Low Density Plasma }\end{array}$} & \multirow{2}{*}{$\begin{array}{l}\text { 5. FUNDING NUMBERS } \\
\text { WU-233-01-OE }\end{array}$} \\
\hline \multicolumn{3}{|c|}{$\begin{array}{l}\text { 6. AUTHOR(S) } \\
\text { Boris V. Vayner, Dale C. Ferguson, David B. Snyder, and C.V. Doreswamy }\end{array}$} & \\
\hline \multicolumn{3}{|c|}{$\begin{array}{l}\text { 7. PERFORMING ORGANIZATION NAME(S) AND ADDRESS(ES) } \\
\text { National Aeronautics and Space Administration } \\
\text { Lewis Research Center } \\
\text { Cleveland, Ohio } 44135-3191\end{array}$} & $\begin{array}{l}\text { AFORMING ORGANIZATION } \\
\text { PORT NUMBER }\end{array}$ \\
\hline \multicolumn{3}{|c|}{$\begin{array}{l}\text { 9. SPONSORINGMONITORING AGENCY NAME(S) AND ADDRESS(ES) } \\
\text { National Aeronautics and Space Administration } \\
\text { Washington, D.C. 20546-0001 }\end{array}$} & $\begin{array}{l}\text { 10. SPONSORINGMONITOAING } \\
\text { AGENCY REPORT NUMBER } \\
\text { NASA TM-107217 }\end{array}$ \\
\hline \multicolumn{4}{|c|}{$\begin{array}{l}\text { 11. SUPPLEMENTARY NOTES } \\
\text { Prepared for the XVII International Symposium on Discharges and Electrical Insulation in Vacuum sponsored by the American } \\
\text { Physical Society, Berkeley, Califomia, July 21-26, 1996. Boris V. Vayner and C.V. Doreswamy, National Research Council- } \\
\text { NASA Research Associate at Lewis Research Center. Dale C. Ferguson and David B. Snyder, NASA Lewis Research Center. } \\
\text { Responsible person, Dale C. Ferguson, organization code, 5470, (216) 433-2298. }\end{array}$} \\
\hline \multicolumn{3}{|c|}{$\begin{array}{l}\text { 12a. DISTRIBUTIONAVAILABILTY STATEMENT } \\
\text { Unclassified - Unlimited } \\
\text { Subject Category } 75 \\
\text { This publication is available from the NASA Center for AeroSpace Information, (301) 621-0390. }\end{array}$} & 12b. DISTRIBUTION CODE \\
\hline \multicolumn{4}{|c|}{ 13. ABSTRACT (Max/mum 200 words) } \\
\hline \multicolumn{4}{|c|}{$\begin{array}{l}\text { An unavoidable step in the process of space exploration is to use high-power, very large spacecraft launched into Earth } \\
\text { orbit. Obviously, the spacecraft will need powerful energy sources. Previous experience has shown that electrical dis- } \\
\text { charges occur on the surfaces of a high-voltage array, and these discharges (arcs) are undesirable in many respects. } \\
\text { Moreover, any high voltage conductor will interact with the surrounding plasma, and that interaction may result in } \\
\text { electrical discharges between the conductor and plasma (or between two conductors with different potentials, for example, } \\
\text { during docking and extravehicular activity). One very important aspect is the generation of electromagnetic radiation by } \\
\text { arcing. To prevent the negative influence of electromagnetic noise on the operation of spacecraft systems, it seems } \\
\text { necessary to determine the spectra and absolute levels of the radiation, and to determine limitations on the solar array bias } \\
\text { voltage that depend on the parameters of LEO plasma and the technical requirements of the spacecraft equipment. This } \\
\text { report describes the results of an experimental study and computer simulation of the electromagnetic radiation generated } \\
\text { by arcing on spacecraft surfaces. A large set of high quality data was obtained during the Solar Array Module Plasma } \\
\text { Interaction Experiment (SAMPIE, flight STS-62) and ground test. These data include the amplitudes of current, pulse } \\
\text { forms, duration of each arc, and spectra of plasma waves. A theoretical explanation of the observed features is presented } \\
\text { in this report too. The elaborated model allows us to determine the parameters of the electromagnetic noise for different } \\
\text { frequency ranges, distances from the arcing site, and distinct kinds of plasma waves. }\end{array}$} \\
\hline \multirow{2}{*}{$\begin{array}{l}\text { 14. SUBJECT TERMS } \\
\text { EMI; Arcing; Plasma }\end{array}$} & & & $\begin{array}{c}\text { 15. NUMBER OF PAGES } \\
30\end{array}$ \\
\hline & & & $\begin{array}{r}\text { 16. PAICE CODE } \\
\text { A03 }\end{array}$ \\
\hline $\begin{array}{l}\text { 17. SECURTY CLASSIFICATION } \\
\text { OF REPORT } \\
\text { Unclassified }\end{array}$ & $\begin{array}{l}\text { 18. SECURITY CLASSIFICATION } \\
\text { OF THIS PAGE } \\
\text { Unclassified }\end{array}$ & $\begin{array}{l}\text { 19. SECURITY CLASSIFICATION } \\
\text { OF ABSTRACT } \\
\text { Unclassified }\end{array}$ & 20. LIMTATTION OF ABSTRACT \\
\hline
\end{tabular}




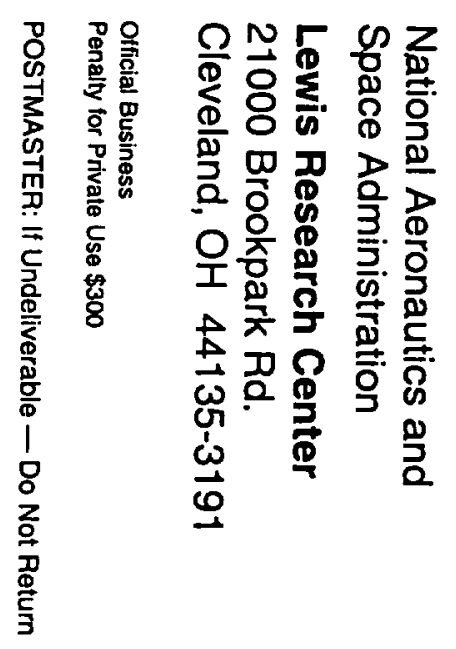

